\title{
An Experimental Investigation of Shale Mechanical Properties Through Drained and Undrained Test Mechanisms
}

\author{
Md. Aminul Islam • Paal Skalle
}

Received: 11 May 2011/Accepted: 22 January 2013/Published online: 12 March 2013

(c) The Author(s) 2013. This article is published with open access at Springerlink.com

\begin{abstract}
Shale mechanical properties are evaluated from laboratory tests after a complex workflow that covers tasks from sampling to testing. Due to the heterogeneous nature of shale, it is common to obtain inconsistent test results when evaluating the mechanical properties. In practice, this variation creates errors in numerical modeling when test results differ significantly, even when samples are from a similar core specimen. This is because the fundamental models are based on the supplied test data and a gap is, therefore, always observed during calibration. Thus, the overall goal of this study was to provide additional insight regarding the organization of the non-linear model input parameters in borehole simulations and to assist other researchers involved in the rock physics-related research fields. To achieve this goal, the following parallel activities were carried out: (1) perform triaxial testing with different sample orientations, i.e., $0^{\circ}, 45^{\circ}, 60^{\circ}$, and $90^{\circ}$, including the Brazilian test and CT scans, to obtain a reasonably accurate description of the anisotropic properties of shale; (2) apply an accurate interpretative method to evaluate the elastic moduli of shale; (3) evaluate and quantify the mechanical properties of shale by accounting for the beddings plane, variable confinement pressures, drained and undrained test mechanisms, and cyclic versus monotonic test effects. The experimental results indicate that shale has a significant level of heterogeneity. Postfailure analysis confirmed that the failure plane coincides nicely with the weak bedding plane. The drained Poisson's ratios were, on average, $40 \%$ or lower than the undrained rates. The
\end{abstract}

Md. A. Islam $(\bowtie) \cdot$ P. Skalle

Department of Petroleum Engineering and Applied Geophysics,

Norwegian University of Science and Technology,

Trondheim, Norway

e-mail: amii@statoil.com drained Young's modulus was approximately $48 \%$ that of the undrained value. These mechanical properties were significantly impacted by the bedding plane orientation. Based on the Brazilian test, the predicted tensile strength perpendicular to the bedding plane was $12 \%$ lower than the value obtained using the standard isotropic correlation test. The cyclic tests provided approximately $6 \%$ higher rock strength than those predicted by the monotonic tests.

Keywords Elastic moduli - Shale mechanical properties . Shale anisotropy $\cdot$ Strength anisotropy $\cdot$ Weak bedding plane Drained $\cdot$ Undrained $\cdot$ Cyclic triaxial test

\section{Introduction}

Most borehole stability problems occur during drilling in overburden shale or shale-like materials, such as mudstones. Borehole instabilities are typically associated with high pore pressures (PPs) in shale located immediately above the hydrocarbon reservoir. Worldwide, there is an increasing tendency to go toward deeper high-pressure/ high-temperature (HPHT) reservoirs. Consequently, the drilling window margin (collapse-fracture) is reduced, and more emphasis is placed on borehole stability predictions to avoid borehole collapse or fracture. Moreover, field observations imply that borehole collapse is strongly dependent on the wellbore orientation, especially in areas where the formation is strongly bedded and where the stress field is non-isotropic. Under such circumstances, accurate information on the rock strength and rock failure behavior in overburden shale is crucial to improve drilling safety. Knowledge of the mechanical properties of shale is vital to implement any 3D shale anisotropy borehole instability model (Crook et al. 2002; Søreide et al. 2009). 
As an example, to implement the modified Cam Clay model for the shale-related borehole instability assessment, mechanical properties and matrix anisotropic parameters, which consist of 21 attributes in total, are required (Søreide et al. 2009). Most of the parameters are related to the mechanical characterization of shale. However, a wide range in their magnitude was observed specifically for the Young's modulus, Poisson's ratio, friction angle, and the shear and bulk moduli. An accurate interpretation, together with sound engineering judgment, appear necessary to evaluate and quantify the mechanical properties of shale. This paper has addressed these concerns by interpreting the results obtained from extensive laboratory testing of shale.

It has previously been assumed that shale is not a reservoir rock and is, thus, not interesting in terms of hydrocarbon production (Hofmann and Johnson 2006). In general, the reservoir sections are the primary target, so shale samples from the overburden sections are limited. Some previous publications on the mechanical properties of tested shale were reported by Closmann and Bradley (1979), Steiger and Leung (1992), and Hoang and Abousleiman (2010). However, the scarcity of deep shale testing samples has lead to a lack of published shale elasticity data. Meanwhile, the interest in shale has increased over the past few years, which was understandably triggered by recognition by the oil industry that the primary migration of oil is incomplete in some shale. Potential challenges to the understanding of shale are shale geochemistry, anisotropy, petrophysical properties, and the response of the seal to pressure as a barrier. The growing interest in shale-gas and caprock integrity for $\mathrm{CO}_{2}$ storage has resulted in a rising demand for fundamental rock property data. Performing work on stimulation wells to create a complex fracture network in a shale-gas field is a difficult task, particularly the drilling of horizontal wells. However, this is the only viable method at this stage to develop a drainage strategy in the shale-gas reservoirs. Fluid flow modeling to develop an analytical solution in this particular event is one current issue where accurate shale property knowledge is essential. Moreover, infill drilling is a practice used by the industry to penetrate interbedded shale-sand formations, requiring the most accurate rock mechanical models to correctly assess the mud weight operational window. Accurate study of all issues requires a database of shale characteristics and its mechanical properties.

The prime consideration when evaluating and modeling borehole stability problems in overburden shale or in an interbedded reservoir is the lack of relevant test data to describe shale properties accurately. In reality, cutting a real shale specimen from an interbedded sand-shale layer is a challenging, costly, and time-consuming task. Experimental data for real shale specimens at the maintained downhole conditions are rare, while data on weak shales (i.e., Pierre-1) are fairly abundant. It is, therefore, a wellaccepted approach to execute experimental investigations on outcrop shale and use the data to provide the necessary material data sets for the fundamental borehole stability model. In practice, fundamental models are calibrated against field cases and readjusted. Many investigators (Johnston 1987; Schmitt et al. 1994; Horsrud et al. 1994; Horsrud 1998; Spaar et al. 1995; Holt et al. 1996; Claesson and Bohloli 2002; Crook et al. 2002; Søreide et al. 2009; Fjær et al. 2008) have, instead, used outcrop shales to calibrate borehole stability models. The present work deals with data sets for Pierre- 1 shale at room temperature and at the high confining pressure present at downhole conditions. It was our intention to compile published shale outcrops test data. This was impossible due to the inconsistency in the reported information and evaluation techniques. It was also unclear as to which types of outcrop batch were used.

Shale is a rock with laminated structure, and the bedding plane orientation determines the mechanical properties of each shale sample. It is a well-accepted statement and a well-defined concept in soil and rock mechanics textbooks that the shale bedding plane leads to borehole instability. Jaeger and Cook (1979) reported the laboratory test results of mechanical properties of layered rocks during failure. A comprehensive study, together with field evidence on the plane of weakness and anisotropy, were introduced and reported in the oil industry by Bradley (1979), Maury and Santarelli (1988), and Aadnøy and Chenevert (1987). Aadnøy and Chenevert (1987) investigated the effects of wellbore inclination, anisotropic stresses, and anisotropic rock strength by modeling highly inclined boreholes. Under certain conditions, the rock would fail along the planes of weakness. Because of the geomechanical properties of the weak plane (alignment of phyllosilicates due to overburden digenesis), slip surfaces may exhibit a significantly higher potential to fail compared with stronger rock units, such as limestone and sandstone. However, this statement is valid only for particular geological formations and may not be applicable in other geological arenas. For example, the same author performed a separate study (Aadnøy et al. 2009) on a tightly folded structure in British Columbia, and it was observed there that the planes of weakness in bedded rocks may lead to borehole collapse. However, in a threedimensional space, there were combinations along wellbore inclinations and azimuths, instead of along the weak planes, where the sample failed. The bedding plane is, thus, a key issue in this study. In general, the critical parameters that cause instability are the planes of weakness, anisotropy, the relative normal stress values on the borehole, the well trajectory, and the relative angle between the borehole and the bedding plane (Bradley 1979; Aadnøy and Chenevert 1987; Aadnøy et al. 2009; Crook et al. 2002; Fjær et al. 2008; Søreide et al. 2009; Islam et al. 2009). 
As discussed earlier, many researchers have studied the properties of clay and shale. Selected test results of mechanical shale properties under drained conditions are published and reported by Closmann and Bradley (1979), Horsrud et al. (1998), Crook et al. (2002), Søreide et al. (2009), and Hoang and Abousleiman (2010). These previous investigations can also be useful for this study to some degree. However, determination of the mechanical properties of shale under drained and undrained test conditions with variable confinement pressure is currently insufficient. To overcome this limitation, this study performed an extensive test program to explore shale heterogeneity and its directional properties. The following parallel activities were performed:

- Characterization and evaluation of shale heterogeneity through a drained and undrained stress path. The mechanical properties and postfailure material behavior were determined under different sample orientations, confinement pressures, and loading steps.

- Determination of the estimated and quantified mechanical properties of shale.

- Proposition of proper data sets for a borehole stability model.

Both compressibility and triaxial tests were utilized, with emphasis on evaluating the elasticity, yielding, and failure response as a function of the confining pressure and bedding plane orientation. The petrophysical testing included porosity, permeability, and bulk- and solid-density measurements. A total of three triaxial tests with different sample orientations (i.e., $0^{\circ}, 45^{\circ}, 60^{\circ}$, and $90^{\circ}$ ), including Brazilian tests and CT scans, were performed to obtain a reasonably accurate description of shale. Moreover, the cyclic stress-dependent rock stiffness and strength were evaluated and compared with the monotonic test results. The method used to achieve relatively consistent test results is briefly discussed at a later stage in this paper.

\section{Materials and Methods}

\subsection{Material and Samples}

The outcrop Pierre-1 shale was used in this study for the following reasons:

- The scarcity of real shale specimens.

- The difficulty in obtaining intact samples of real shale specimens due to splitting along the bedding planes during the coring process.

- Mechanically, Pierre-1 shale exhibits plastic and anisotropic behavior that could be used in borehole simulation modeling of real shale.
The outcrop shale block was preserved by wax when received. A core barrel was used to drill the core samples from a large block stored in laboratory-grade oil (Mar$\mathrm{col}^{\mathrm{TM}}$ ) to prevent fluid losses. Both the drilling and the subsequent end-grinding of the plugs to obtain sufficiently plane and parallel end surfaces were performed whilst surrounded in the same oil. The prepared samples were subsequently stored in $\mathrm{Marcol}^{\mathrm{TM}}$ until they were assembled in the test cell to avoid desiccation effects.

The samples were equilibrated to the brine $(3.5 \mathrm{w} \%$ $\mathrm{NaCl}$ ) prior to ramping up stresses to consolidation level, so as the Pierre is a outcrop material with initial low stress levels, this should assume saturation close to 1 during the tests. Porosity was determined from fluid loss by heating typically to about $105{ }^{\circ} \mathrm{C}$.

The test samples were $38 \mathrm{~mm}$ in diameter and had a length of approximately two times the diameter. A summary of the test specimens and other necessary information are presented in Table 1 . The mineralogical and petrophysical properties of the Pierre-1 shale used are presented in Tables 2, 3, and 4.

We used samples from two neighboring blocks. All triaxial samples had densities between 2.32 and $2.34 \mathrm{~g} /$ $\mathrm{cm}^{3}$, with an average density of $2.33 \pm 0.005 \mathrm{~g} / \mathrm{cm}^{3}$. We also completed separate density and porosity measurements on the two blocks from which we drilled the samples. From the loss of pore fluid measurement, the densities and porosities were determined to be $2.33 \mathrm{~g} / \mathrm{cm}^{3}$ and $23.2 \%$ (block 2) and $2.34 \mathrm{~g} / \mathrm{cm}^{3}$ and $22.4 \%$ (block 3), respectively, i.e., they were fairly similar.

\subsection{Sample Selection}

CT scans were performed to check for possible heterogeneities in the test samples. To illustrate the heterogeneity effect of Pierre-1 shale, two examples of CT scans (radial slices) are presented in Fig. 1a, b. Lighter areas generally correspond to denser (higher absorption) material. The very light color on one of the scans is likely calcite (Fig. 1a). Such samples were discarded from the consolidated isotropic undrained triaxial compression tests (CIU). The other image contains a less light, gray region/layer (Fig. 1b), which is not calcite but likely represents a more silty region. Such samples were used in the consolidated isotropic drained triaxial compression tests (CID).

\subsection{Bedding Plane and Loading}

The bedding plane orientation in the triaxial test is denoted by the angle $\theta$, which is measured clockwise from the loading direction relative to the bedding plane (Fig. 2). The monotonic CIU tests were performed with angles of $0^{\circ}$, $45^{\circ}, 60^{\circ}$, and $90^{\circ}$ between the load axis and the bedding 
Table 1 Test matrix of the triaxial testing of Pierre-1 shale

\begin{tabular}{|c|c|c|c|c|c|c|c|c|c|c|c|}
\hline \multirow[t]{2}{*}{ Test ID } & \multicolumn{3}{|l|}{ Size } & \multicolumn{2}{|c|}{ Consolidation } & \multicolumn{4}{|c|}{ At failure } & \multicolumn{2}{|l|}{ Test time } \\
\hline & $\begin{array}{l}\text { Length } \times \text { diameter } \\
(\mathrm{mm})\end{array}$ & $\begin{array}{l}\theta \\
\left(^{\circ}\right)\end{array}$ & $\rho(\mathrm{g} / \mathrm{cc})$ & $\begin{array}{l}\sigma_{\mathrm{c}} \\
(\mathrm{MPa})\end{array}$ & $\begin{array}{l}P_{\mathrm{p}} \\
(\mathrm{MPa})\end{array}$ & $\begin{array}{l}\sigma_{\mathrm{z}} \\
(\mathrm{MPa})\end{array}$ & $\begin{array}{l}\sigma_{\mathrm{r}} \\
(\mathrm{MPa})\end{array}$ & $\begin{array}{l}P_{\mathrm{p}} \\
(\mathrm{MPa})\end{array}$ & $\begin{array}{l}\text { Strain rate } \\
\left(\mathrm{s}^{-1}\right)\end{array}$ & $\begin{array}{l}\text { Up to } \\
\text { consolidation (h) }\end{array}$ & $\begin{array}{l}\text { Triaxial } \\
\text { loading }(\mathrm{h})\end{array}$ \\
\hline CIU_192_2-32 & $76 \times 37.62$ & 90 & 2.33 & 25 & 10 & 50.90 & 25 & 14.90 & $1.50 E-07$ & 38.98 & 29.42 \\
\hline CIU_192_2-33 & $75.92 \times 37.66$ & 90 & 2.33 & 20 & 10 & 41.14 & 20 & 13.90 & $1.00 E-07$ & 45.80 & 42.33 \\
\hline CIU_192_2-34 & $75.99 \times 37.66$ & 90 & 2.33 & 16 & 9.9 & 31.60 & 16 & 12.55 & $1.00 E-07$ & 40.12 & 39.82 \\
\hline CIU_192_3-6 & $75.9 \times 37.96$ & 0 & 2.33 & 20 & 10 & 35.97 & 20 & 15.58 & $1.40 E-07$ & 26.17 & 45.24 \\
\hline CIU_192_3-7 & $75.88 \times 37.93$ & 0 & 2.32 & 25 & 9.9 & 46.26 & 25 & 17.35 & $1.90 E-07$ & 28.24 & 33.06 \\
\hline CIU_192_3-8 & $75.88 \times 37.78$ & 0 & 2.32 & 30 & 9.91 & 55.39 & 30 & 19.5 & $2.00 E-07$ & 31.13 & 31.25 \\
\hline CIU_192_3-16 & $76.04 \times 37.76$ & 45 & 2.33 & 25 & 9.91 & 46.44 & 25 & 15.93 & $1.60 E-07$ & 29 & 33 \\
\hline CIU_192_3-19 & $75.17 \times 37.71$ & 45 & 2.33 & 18 & 9.93 & 32.08 & 18 & 14.12 & $1.70 E-06$ & 25 & 27 \\
\hline CIU_192_3-20 & $75.96 \times 37.75$ & 45 & 2.33 & 30 & 10.01 & 55.36 & 30 & 17.99 & $1.7 E-07$ & 32 & 33 \\
\hline CIU_192_3-11 & $75.65 \times 37.73$ & 60 & 2.33 & 25 & 10.02 & 46.00 & 25 & 16.20 & $1.00 E-07$ & 69.5 & 40.5 \\
\hline CIU_192_3-12 & $75.83 \times 37.74$ & 60 & 2.34 & 18 & 10.03 & 32.64 & 18 & 13.50 & $1.00 E-07$ & 65 & 63 \\
\hline CIU_192_3-13 & $76.03 \times 37.71$ & 60 & 2.34 & 30 & 9.98 & 54.17 & 30 & 17.57 & $1.00 E-07$ & 72 & 70 \\
\hline CID_192_2-35 & $75.96 \times 37.72$ & 90 & 2.33 & 17 & 10.07 & 38.60 & 17 & 10.08 & $2.30 E-08$ & 85 & 245 \\
\hline CID_192_3-09 & $75.75 \times 37.77$ & 0 & 2.33 & 17 & 9.97 & 36.80 & 17 & 9.92 & $2.00 E-08$ & 85 & 457 \\
\hline
\end{tabular}

Table 2 Mineralogical composition of Pierre-1 shale determined by X-ray diffraction spectroscopy (with weight in terms of bulk percentage)

\begin{tabular}{llllllllllll}
\hline Quartz & k-fsp & Plag & Chl & Ka & Mi/Ill & ML & Sm & Calc & Sid & Dol/Ank & Pyr \\
\hline 20.1 & 0.7 & 15.7 & 2.2 & 6.8 & 16.6 & 0.3 & 31.5 & 1.8 & 0.7 & 1.8 & 2.0
\end{tabular}

Chl chlorite, $\mathrm{Ka}$ kaolinite, $\mathrm{Mi} / \mathrm{Ill}$ mica and illite, $M L$ mixed layer, $\mathrm{Sm}$ smectite, Sid siderite, Dol dolomite, Ank ankerite, Pyr pyrite

Table 3 Semi-quantitative X-ray diffraction analysis: fine percentage $(<4 \mu \mathrm{m})$

\begin{tabular}{|c|c|c|c|c|c|c|c|c|c|c|c|}
\hline Quartz & k-fsp & Plag & Chl & $\mathrm{Ka}$ & $\mathrm{Mi} / \mathrm{Ill}$ & ML & $\mathrm{Sm}$ & Calc & Sid & Dol/Ank & Pyr \\
\hline 7.4 & 0.3 & 1.8 & 7.9 & 8.7 & 15.2 & 0.0 & 57.8 & 0.2 & 0.1 & 0.1 & 0.5 \\
\hline
\end{tabular}

Table 4 Petrophysical and physical properties of the Pierre-1 shale

\begin{tabular}{lllll}
\hline $\begin{array}{l}\text { Block } \\
\#\end{array}$ & $\begin{array}{l}\text { Bulk density } \\
(\text { saturated })(\mathrm{g} /\end{array}$ & $\begin{array}{l}\text { Bulk density } \\
(\mathrm{dry})\left(\mathrm{g} / \mathrm{cm}^{3}\right)\end{array}$ & $\begin{array}{l}\text { Water } \\
\text { content } \\
(\%)\end{array}$ & $\begin{array}{l}\text { Porosity } \\
(\%)\end{array}$ \\
\hline 2 & 2.33 & 2.10 & 9.9 & 23.2 \\
3 & 2.34 & 2.12 & 9.6 & 22.4 \\
\hline
\end{tabular}

plane. The same is true for the CID tests, with the angles of $0^{\circ}$ and $90^{\circ}$. The postfailure samples are presented in Fig. 3 . Through a postmortem analysis of the tests samples, it is observed that, in most cases, the failure plane transverses nicely through the weak bedding plane.

\subsection{Brazilian Test}

The tensile strength of rocks is among the most important parameters influencing rock deformability, rock crushing, and blasting results. To calculate the tensile strength from the indirect tensile (Brazilian) test, one must know the principal tensile stress, in particular, at the disc center, where a crack initiates. This stress can be calculated by an analytical solution given by Claesson and Bohloli (2002). A Brazilian test was conducted to estimate the indirect tensile strength at both $\theta=90^{\circ}$ and $0^{\circ}$ conditions. One sample (length $=19.55 \mathrm{~mm}$ and diameter $=37.70 \mathrm{~mm}$ ) with a bulk density of $2.32 \mathrm{~g} / \mathrm{cm}^{3}$ showed a rock tensile strength of 0.62 and $0.76 \mathrm{MPa}$ at $\theta=90^{\circ}$ and $0^{\circ}$, respectively. This measured tensile strength through $\theta=0^{\circ}$ is $12 \%$ lower than the result of the standard isotropic correlation given by Claesson and Bohloli (2002). The test results also indicated that the tensile strength is higher for vertical than for horizontal bedding.

\subsection{Triaxial Testing}

A schematic drawing is presented in Fig. 4 to illustrate the methods of collecting data using the triaxial test. 
Fig. 1 CIU and CID tests for Pierre-1 shale; a,

b heterogeneous nature of shale. The very light color on one of the scans is probably calcite (a) A less light, gray region/layer (Fig. 1b) is not calcite but probably a more silty region
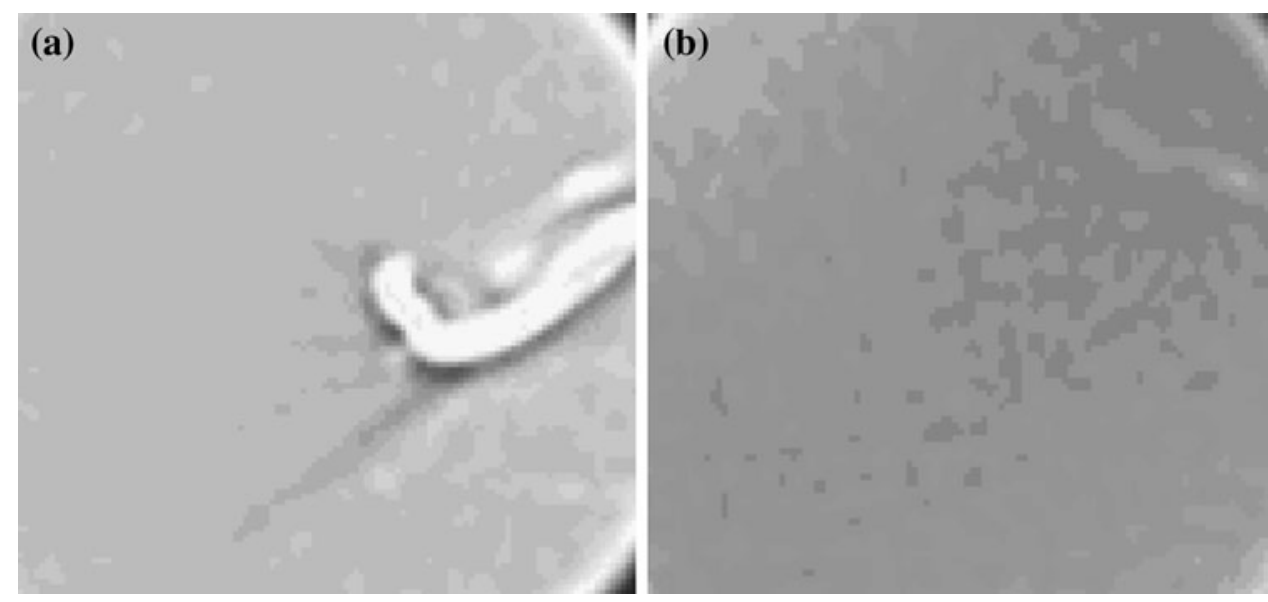

Fig. 2 Principle drawing including bedding angle and loading; a drilled normal to bedding $\left(\theta=0^{\circ}\right)$, b drilled parallel to bedding $\left(\theta=90^{\circ}\right)$, and $\mathbf{c}$ drilled inclined to normal to bedding $(\theta=$ inclined). The angle $\theta$ is measured clockwise from the loading direction relative to the bedding plane

Fig. 3 Postfailure views of the Pierre-1 shale samples performed through monotonic loading; a loading normal to bedding $\left(\theta=0^{\circ}\right)$, b loading $45^{\circ}$ to the normal to bedding $\left(\theta=45^{\circ}\right)$, c loading $60^{\circ}$ to the normal to bedding $\left(\theta=60^{\circ}\right)$, and $\mathbf{d}$ loading parallel to bedding $\left(\theta=90^{\circ}\right)$
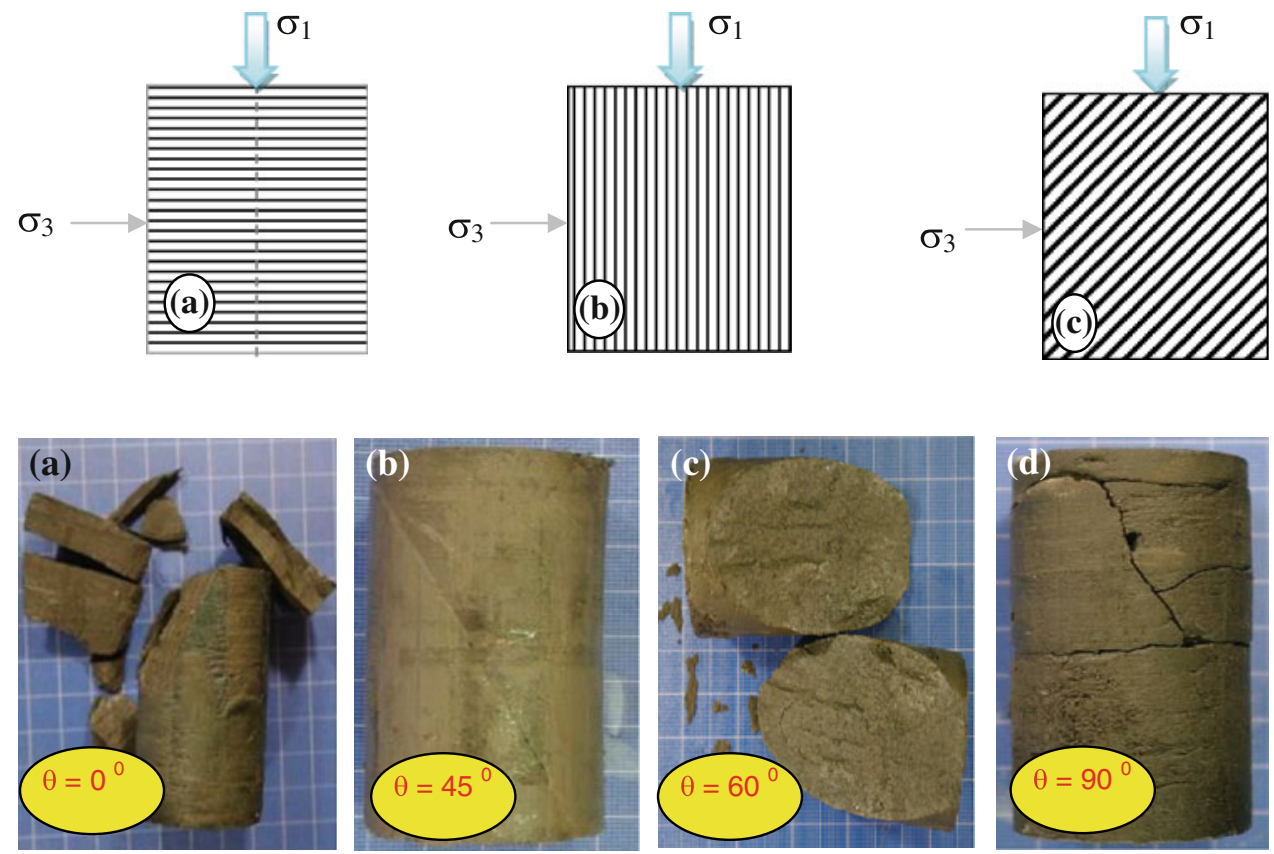

\subsection{Drained and Undrained Test Mechanisms}

During drilling in low permeable shale, a typical undrained stress relaxation response is observed at the borehole wall. With extended time, excess PP will dissipate and equilibrate with the surrounding pressure. A redistribution of stresses might provide a time-delayed failure in the shale formation.

In this study, fluid permeability was measured with the pulse-decay technique at a constant confining pressure (15 MPa). This is a standard pulse-decay method on samples subjected to hydrostatic stress. We used brine as the contacting pore fluid. The measurements were performed carefully to avoid effects from temperature variations and other factors influencing the results.

Due to the low shale permeability, steady-state type measurement techniques are not generally applied. Instead, techniques based on transient measurements are used (Horsrud et al. 1998). We used a technique where a thin (6$\mathrm{mm}$ ) circular disk (38 $\mathrm{mm}$ in diameter) was placed into a pressure cell, where PP and hydrostatic confining pressure could be applied separately. After loading to pre-determined levels of PP and confining pressure, ample time was given for the sample to consolidate. The PP was increased by $0.5 \mathrm{MPa}$ on one side of the sample and reduced by the same amount on the other side (see Fig. 5). The decay in this pressure difference was then recorded by a differential pressure transducer, and the permeability was calculated from this time response.

From the permeability $(k)$ measurements within a confining pressure of $15 \mathrm{MPa}$ and a PP of $5 \mathrm{MPa}, k$ was 14 and $49 \eta \mathrm{D}$ at $\theta=0^{\circ}$ and $90^{\circ}$, respectively. Because shale is expected to be anisotropic, it is reasonable to expect the permeability to be anisotropic and to expect the largest 

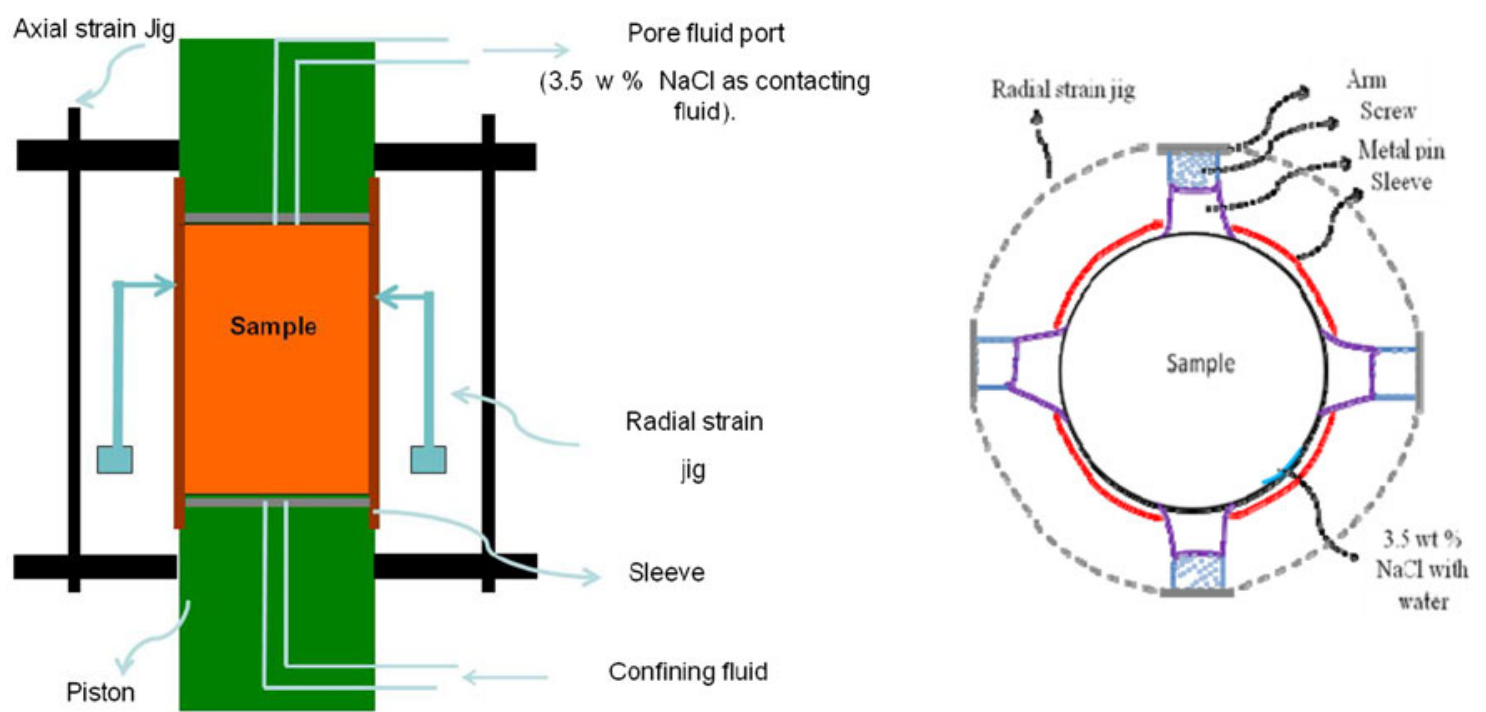

Fig. 4 Principle sketch of the interior of a triaxial cell, showing the loading piston with fluid ports, optional sintered plates for fluid distribution, a radial strain jig (suspended from the specimen) measuring two orthogonal diameters, and an axial strain jig measuring the change in sample length between the pistons. It is also possible to measure axial strain directly on the sample, to measure radial strain in more than two directions, or measure the change in circumference by a chain around the sample (after Fjær et al. 2008)

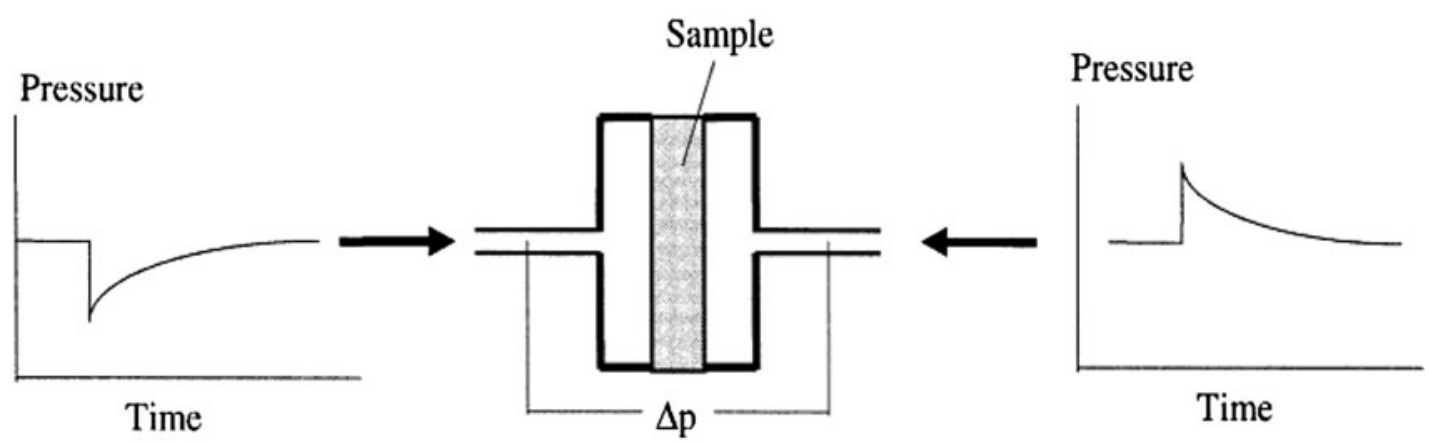

Fig. 5 Illustration of the pressure transient method used for permeability estimation (Horsrud et al. 1994)

values parallel to the bedding. Islam et al. (2009) reported that the magnitude of the consolidation time for the finite diffusive length adjacent to the borehole wall was only in the range of hours and days for samples with a permeability of $100 \eta \mathrm{D}$. Therefore, drained tests were necessary for time-delayed material failure analysis. The drained stiffness was somewhat lower than the undrained stiffness, as drained stiffness accounts for effective stress.

Generally, in drained tests, the outlets through the pistons will be open such that the pore fluid pressure can be maintained at any prescribed value. During the hold periods, the PP equilibration is expected to take place inside the sample. During the testing of shale, the drained condition means that the test must run sufficiently slowly to avoid unacceptable pressure build-up when the sample deforms. In this case, a strain rate of $2 \times 10^{-8} \mathrm{~s}^{-1}$ was maintained until failure. How long the drained test will take is fairly difficult to estimate and basically depends on the strain rate used during the triaxial loading of the specific sample. The standard procedure is to estimate this strain rate from the consolidation behavior in the initial hydrostatic phase, which depends on the specific sample, confining stress, and PP, as well as how effective the PP drainage is working for a given sample. The desired strain rate for the drained condition is often 10 times slower than that for the undrained condition. For example, based on an assumed strain rate of $2 \times 10^{-7} \mathrm{~s}^{-1}$ (and a 10-mm axial strain at failure) and $24 \mathrm{~h}$ initial consolidation, $68 \mathrm{~h}$ was required to complete an undrained test (sample drilled parallel to the bedding; $\theta=90^{\circ}$ ), whereas for the drained test, it would be approximately 10 times longer. A brief discussion is included on this topic in the next section. From a theoretical point of view, drained conditions mean that the PP in the sample is an independent variable, while for undrained tests, it is a dependent variable. In real-life borehole stability simulations, both drained and undrained 
rock mechanical properties are necessary because they depend on the time scale. In the case of a short borehole simulation, undrained rock properties can be used, whereas for long simulations, the drained rock properties are applied.

\subsection{Triaxial Testing of Shales}

The triaxial tests were run as consolidated drained and undrained tests in a servo-controlled load frame. Consolidated undrained (CIU) tests were selected for the testing of shales (Steiger and Leung 1992; Nakken et al. 1989; Horsrud et al. 1998). The procedure was adopted from soil testing (e.g., Head 1984). This test consisted of three distinct phases:

- Loading to the predetermined level of confining pressure and PP.

- Consolidating, maintaining a constant confining pressure, and allowing drainage of the pore fluid against a constant PP.

- Undrained axial loading under a constant axial displacement rate beyond failure of the sample.

The internal instrumentation of the test sample is shown in Fig. 4. In addition to the measurements of the external load, pressure, and deformations, the PP on both ends of the sample were recorded, and acoustic wave trends in both the axial and radial directions were also recorded.

CIU tests were performed at angles of $0^{\circ}, 45^{\circ}, 60^{\circ}$, and $90^{\circ}$ between the sample axis and the bedding plane. In addition, two CID tests were performed to obtain the effective stress parameters. For triaxial testing, all of the samples were consolidated up to $10 \mathrm{MPa}$ of PP. The confining pressure was ramped up to 20,25 , and $30 \mathrm{MPa}$ to simulate a closer range of downhole effective stress conditions.

The samples were left for $24 \mathrm{~h}$ to establish consolidation. We monitored the strain (deformation) so as to evaluate when consolidation would be sufficient. In general, $24 \mathrm{~h}$ of consolidation for our sample geometries is considered to be a sufficient amount of time. The time dependency of the consolidation phase was also used to determine the loading rate during the main triaxial phases (which were run in a constant strain mode). In some undrained tests, the strain rate was $1-2 \times 10^{-7} \mathrm{~s}^{-1}$. For the drained tests, the rate was approximately $2 \times 10^{-8} \mathrm{~s}^{-1}$. In addition, the size of the test sample and the time required to perform a test depended highly on the permeability of the shale (Nes et al. 1998; Islam et al. 2009; Loret et al. 2001) and the fluid viscosity.

A typical response from the triaxial loading of the consolidation type is shown in Fig. 6. The drained test was extremely time consuming up to sample failure (see
Fig. 6e). For a drained test, approximately 20 days was required to reach yielding with a strain rate of $2 \times 10^{-8} \mathrm{~s}^{-1}$. This is the main reason for running the triaxial loading part in the undrained mode. Concepts from soil mechanical testing can be applied to assist in determining when consolidation is complete and also when the appropriate displacement rate is achieved in the undrained part of the test (Katsube et al. 1991). Determination of the strain rate in the undrained part was also based on the consolidation response of the sample to ensure that PP equilibrium was achieved throughout the sample. To reduce the test time as much as possible, both axial and radial drainage of the sample were included.

In the case of CIU tests conditions, a total test time of 2-4 days, on average, was required, including consolidation of approximately $20-25 \mathrm{~h}$ to failure. The bedding plane sample at $60^{\circ}$ took a maximum of 5 days to fail (Fig. 6d). From the material stiffness analysis, the strongest sample was determined to be the sample drilled parallel to the bedding and would normally take a longer time to fail.

The PP increased up to a certain level with increasing axial stress, after which the PP tended to decrease until the sample failed. The response of PP during triaxial testing is presented in Fig. 6. Referring to Fig. 6a, with $30 \mathrm{MPa}$ of confining pressure, the net PP increased $9 \mathrm{MPa}$, but at the failure position, the $\mathrm{PP}$ dropped $7 \mathrm{MPa}$ and decreased further. This decrease indicates that the sample dilates before failure. In general, induced cracks or microfractures were created before the material reached failure. Basically, induced cracks or microfractures increase the pore volume (Fjær et al. 2008). The increased pore volume led to material dilatancy, consequently reducing the PP. In general, the failure position is controlled by increased pore volume, which reduces the PP. The development of PP under different bedding planes and confining pressures is presented in Fig. 6a-f. From this analysis, PP changed due to the change of the bedding plane. The confining pressure was quantified. The PP development versus confining pressure response is shown in Fig. 6f. This analysis indicates that the PP development reached a maximum at $0^{\circ}$ bedding and was the lowest for $90^{\circ}$ bedding. For the CID condition, PP was constant (see Fig. 6e). Thus, the actual effective stress-related parameters can be obtained through such tests.

PP development is linked with the effective stress to define material failures. According to the Mohr-Coulomb failure envelope, a material with $0^{\circ}$ or $45^{\circ}$ bedding to normal will reach the failure line prior to other orientations. One anomaly is indicated by a dotted circle at $90^{\circ}$ bedding in Fig. 6e. The anomaly may be due to a contribution in the pore-pressure fluid volume or uncertainities related to existing cracks. The stiffness analysis trends are presented in Fig. 6 b, which shows that samples drilled parallel to the 
Fig. 6 Triaxial testing of Pierre-1 shale subjected to consolidation, triaxial loading, and development of PP; a the timeline shows the development of PP and failure load with variable confinement pressure, at sample $\theta=0^{\circ}, \mathbf{b}$ effect of bedding plane on PP and failure load, c variable confining pressure to estimate failure load and to develop PP against total test time at $\theta=90^{\circ}, \mathbf{d}$ material failure and PP response under constant confinement pressure with different bedding plane orientations, e failure response against total test time for CID for two samples, $\theta=0^{\circ}$ and $90^{\circ}$, f PP and failure response against axial deformation subjected to variable confinement pressure. The two dotted circles indicate abnormal strain rate and unusual PP development
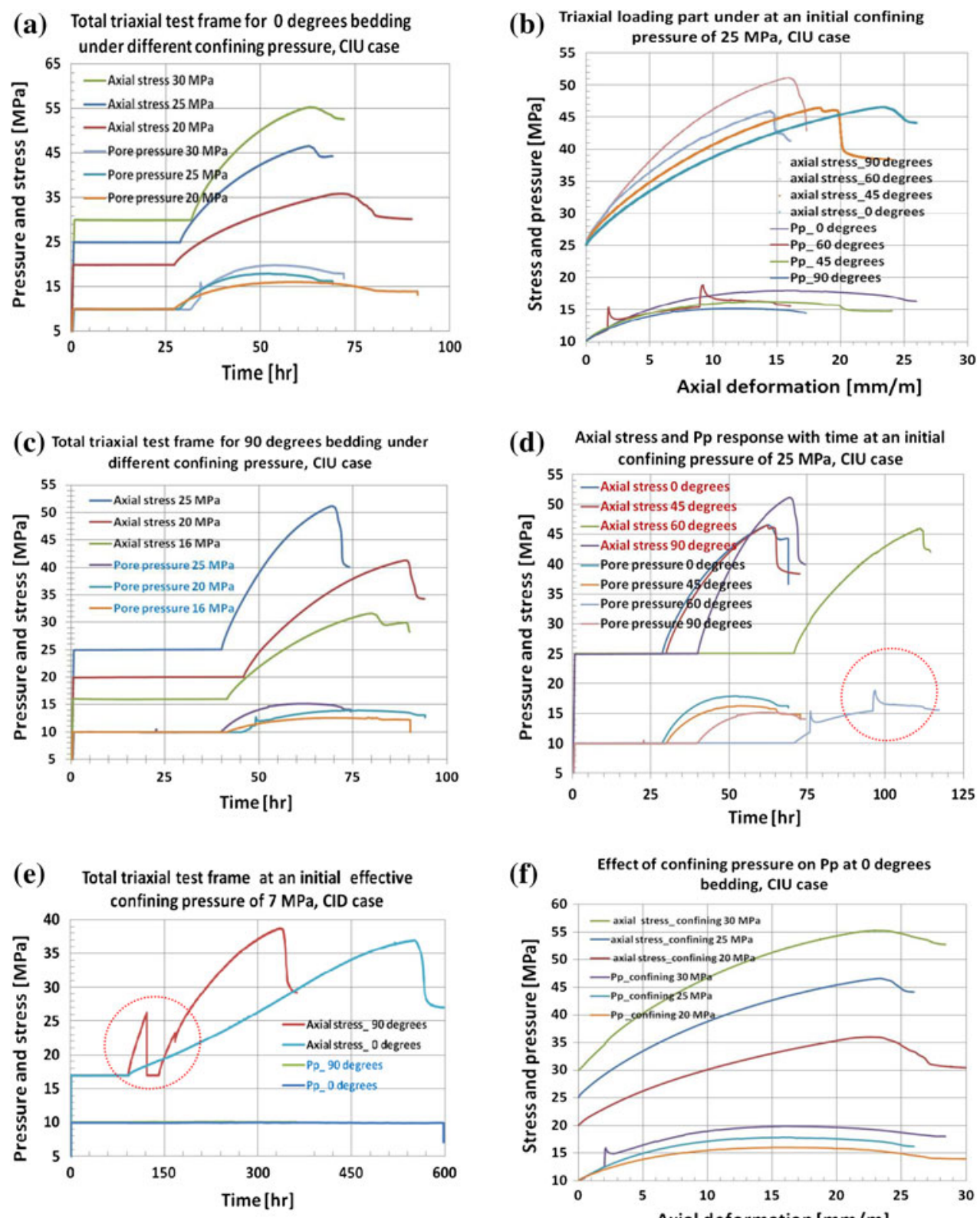

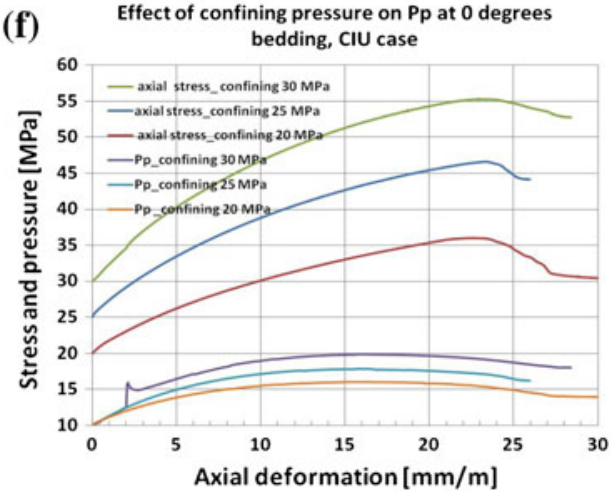

bedding are the strongest. A summary of the rock failurerelated data applicable at different sample orientations is presented in Table 1. The summary implies that net PP developments during CIU tests are not similar. The bedding plane and material heterogeneity are two key concerns to control the material failure and the development of PP.

\section{Elastic Moduli of Shale-Theory}

The elastic moduli of a material are primarily described by its Young's modulus $(E)$ and Poisson's ratio $(v)$. These two parameters are interpreted in this study using the triaxial test results through a stress-strain trend analysis. Several simplifications have been introduced to calculate the elastic properties of shale from the triaxial tests. One key simplification is that the elastic stress-strain response is assumed to be linear. This is generally not the case for both the hydrostatic and triaxial phases. Thus, when presenting the elastic moduli, it is essential to define how the interpretation has been made. The following alternatives are applicable to estimate the Young's modulus (Wood 1990; Fjær et al. 2008):

- Initial modulus, given as the initial slope of the stressstrain curve.

- Secant modulus, measured at a fixed percentage of the peak stress. 
Fig. 7 Elastic moduli estimation techniques of shale; a Young's modulus, b Poisson's ratio. The symbol $\psi$ is the dilatancy angle and $v$ is the Poisson's ratio. In practice, the ductile region may be very small
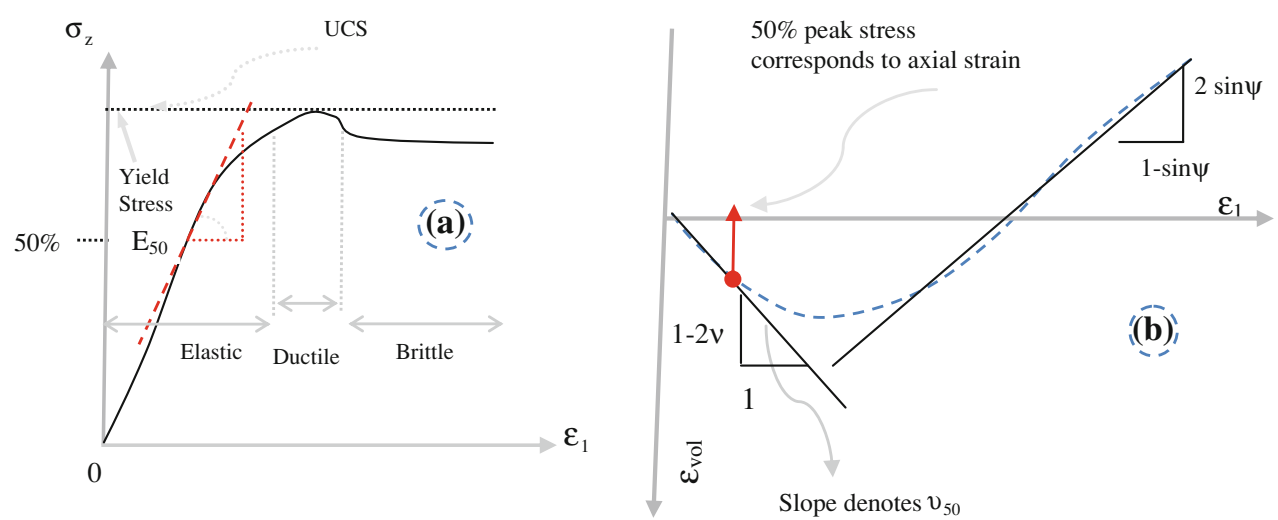

- Tangent modulus, given at a specific percentage of the peak stress.

- Average modulus, given within a specific maximum and minimum stress level.

Of these alternatives, the tangent modulus at $50 \%$ of the peak stress value was chosen in this study simply because it is the most widely used method.

The Young's modulus was determined as the tangent modulus measured at $50 \%$ of the peak stress (see Fig. 7a) and is, therefore, denoted as $E_{50}$. The Poisson's ratio was determined from the inclination of a straight line that passes from the origin to the point of the curve that corresponds to $50 \%$ of the peak stress in an $\varepsilon_{\mathrm{vol}}$ versus $\varepsilon_{1}$ diagram (see Fig. $7 b$ ), and is, therefore, denoted as $v_{50}$.

According to the American Society for Testing and Materials (ASTM) and International Society for Rock Mechanics (ISRM) standards, it is recommended to use the deformation rates at $50 \%$ of the peak stress level for the determination of $v$. However, if the curve is strongly nonlinear, complete information can only be given if the entire curve is presented. Shale is an anisotropic material, thus, the Poisson's ratio and the Young's modulus are not the proper parameters to describe the mechanical behavior. The elastic stiffness tensor, defined by Fjær et al. (2008), is required for an accurate description of the shale.

\section{Elastic Moduli-Results and Discussion}

\subsection{Strain Measurements}

We have carefully leveled the strike and slip directions of the test samples. One arm of the cantilever was placed in the strike direction (along the bedding), and another arm was placed in the slip direction (perpendicular to the bedding). Radial deformation was measured by two pairs of calipers (pairs \#1 and \#2) mounted orthogonal to one another. One of the pairs always measured deformation along the strike direction.
Because we performed several tests along different bedding inclinations, a summary of sample orientations and caliper positions to measure the radial deformations are presented below:

- Perpendicular to bedding $\left(\theta=0^{\circ}\right)$ : pair $\# 1$ measures deformation along the strike direction.

- Angle to bed $\left(\theta=45^{\circ}\right)$ : pair \#1 measures deformation along the dip direction.

- Angle to bed $\left(\theta=60^{\circ}\right)$ : pair \#1 measures deformation along the dip direction.

- Parallel to bedding $\left(\theta=90^{\circ}\right)$ : pair \#1 measures deformation along the slip direction.

\subsection{Elastic Moduli of Shale-the CIU Case}

During the CIU testing of shale, the confining stress was generally kept constant on a total stress basis. However, the effective confining stress is affected by the PP response. Consequently, the anisotropic effective stress parameters were difficult to obtain because the radial effective stress changed. In the CIU test conditions, the stiffness of the water was also taken into account and, because there was no volumetric change (because water is incompressible), the Young's modulus was expected to be greater than for the CID case. In general, for partially undrained conditions, the stiffness is higher and the volumetric strain is reduced (Holt et al. 2011; Rozhko 2011).

As mentioned earlier, the Young's modulus normally appeared to be greater for the undrained conditions. In addition, the higher the confining stresses, the higher the Young's modulus for the same type of test and the same angle to the bedding. For similar confining pressures, the Young's modulus was greater (the material is stiffer) for loading parallel to the bedding and smaller for loading perpendicular to the bedding. The stress-strain curves are presented in Fig. 8 to show how the material stiffness varied due to the effects of confining pressure and of the bedding plane. The Young's moduli and the Poisson's ratios were 
Fig. 8 Stress-strain response subjected to different confining pressures and bedding angles; $\mathbf{a} \theta=0^{\circ}, \mathbf{b} \theta=90^{\circ}, \mathbf{c} \theta=45^{\circ}$, and $\mathbf{d} \theta=60^{\circ}$. At low confinement pressure, natural microfractures cause non-linear stress-strain curve response (marked with the dotted ellipse in a)
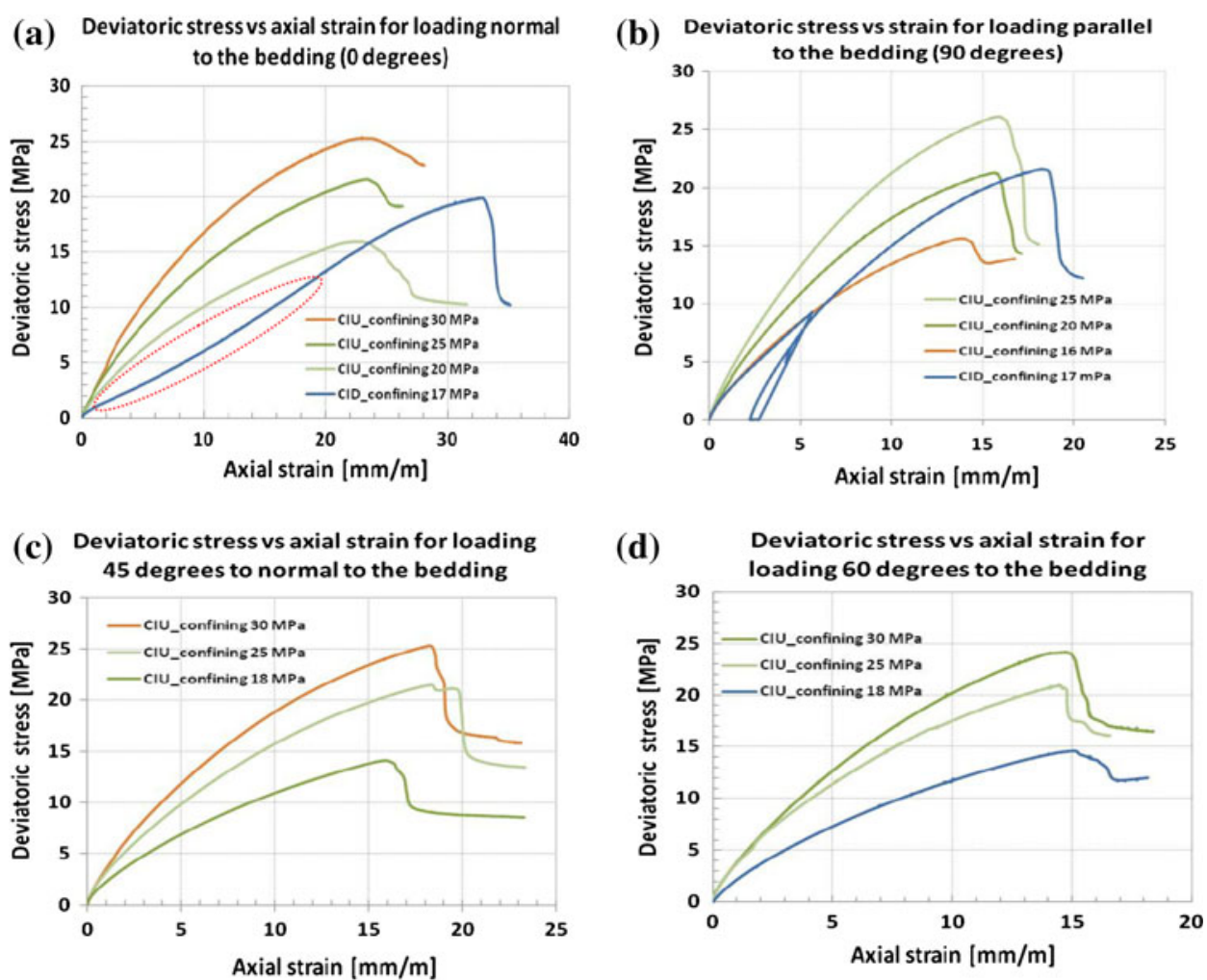

Table 5 Estimated elastic moduli of Pierre-1 shale associated with different bedding planes and confinement pressures

\begin{tabular}{|c|c|c|c|c|c|c|c|c|c|c|}
\hline$\theta\left({ }^{\circ}\right)$ & $\sigma_{\mathrm{c}}(\mathrm{MPa})$ & $E_{50}(\mathrm{GPa})$ & $v_{1}$ & $v_{2}$ & $\mathrm{G}_{1}(\mathrm{GPa})$ & $\mathrm{G}_{2}(\mathrm{GPa})$ & $\mathrm{K}_{1}(\mathrm{GPa})$ & $\mathrm{K}_{2}(\mathrm{GPa})$ & $\lambda_{1}(\mathrm{GPa})$ & $\lambda_{1}(\mathrm{GPa})$ \\
\hline \multicolumn{11}{|l|}{ CIU } \\
\hline 0 & 20 & 1.360 & 0.44 & 0.54 & 0.47 & 0.44 & 3.78 & 5.67 & 3.46 & 5.96 \\
\hline 0 & 25 & 1.550 & 0.52 & 0.53 & 0.51 & 0.51 & 12.92 & 8.61 & 13.26 & 8.95 \\
\hline 0 & 30 & 1.900 & 0.41 & 0.56 & 0.67 & 0.61 & 3.52 & 5.28 & 3.07 & 5.68 \\
\hline 45 & 18 & 1.150 & 0.61 & 0.34 & 0.36 & 0.43 & 1.74 & 1.20 & 1.98 & 0.91 \\
\hline 45 & 25 & 1.900 & 0.46 & 0.35 & 0.65 & 0.70 & 7.92 & 2.11 & 7.48 & 1.64 \\
\hline 45 & 30 & 2.300 & 0.58 & 0.38 & 0.73 & 0.83 & 4.79 & 3.19 & 5.28 & 2.64 \\
\hline 60 & 18 & 1.450 & 0.62 & 0.33 & 0.45 & 0.55 & 2.01 & 1.42 & 2.31 & 1.06 \\
\hline 60 & 25 & 2.400 & 0.72 & 0.38 & 0.70 & 0.87 & 1.82 & 3.33 & 2.28 & 2.75 \\
\hline 60 & 30 & 2.600 & 0.56 & 0.30 & 0.83 & 1.00 & 7.22 & 2.17 & 7.78 & 1.50 \\
\hline 90 & 16 & 1.730 & 0.70 & 0.31 & 0.51 & 0.66 & 1.44 & 1.52 & 1.78 & 1.08 \\
\hline 90 & 20 & 2.200 & 0.75 & 0.32 & 0.63 & 0.83 & 1.47 & 2.04 & 1.89 & 1.48 \\
\hline 90 & 25 & 2.650 & 0.65 & 0.29 & 0.80 & 1.03 & 2.94 & 2.10 & 3.48 & 1.42 \\
\hline \multicolumn{11}{|l|}{ CID } \\
\hline 0 & 17 & 0.640 & 0.1 & 0.1 & 0.29 & 0.29 & 0.27 & 0.27 & 0.07 & 0.07 \\
\hline 90 & 17 & 1.560 & 0.19 & 0.095 & 0.66 & 0.71 & 0.84 & 0.64 & 0.40 & 0.17 \\
\hline
\end{tabular}

$\theta=$ angle between loading and normal of the bedding planes, $\sigma_{\mathrm{c}}=$ confinement pressure, $E_{50}=$ Young's modulus, $v_{1}$ and $v_{2}=$ Poisson's ratios, $\mathrm{G}_{1}$ and $\mathrm{G}_{2}=$ shear moduli, $\mathrm{K}_{1}$ and $\mathrm{K}_{2}=$ bulk moduli, $\lambda_{1}$ and $\lambda_{2}=$ elastic moduli (Lamé parameters)

calculated from Fig. 8, in both drained and undrained test conditions. The determined elastic parameters, including both $E_{50}$ and $v_{50}$, together with the bulk modulus, shear modulus, and Lamé modulus, are summarized in Table 5. The effect of the temperature on these elastic moduli is not included in this paper. Similar studies (Horsrud et al. 1998;
Søreide et al. 2009) indicate that, at a downhole temperature of $120{ }^{\circ} \mathrm{C}$, a significant reduction in both stiffness (approx. $-25 \%$ ) and strength (approx. $-35 \%$ ) of the shale is observed. According to Søreide et al. (2009), the downhole undrained stiffness for North Sea shale at $140{ }^{\circ} \mathrm{C}$ is $57 \%$ of the stiffness at room temperature. One possible 
countermeasure of the temperature increase is to improve the saturation of the sample, weaken the rock frame, and/or increase the fluid modulus, which would reduce capillary effects. This can contribute significantly to the strength of rocks with small pores (Schmitt et al. 1994; Papamichos et al. 1997). In general, it was found that, compared with sandstone, the response of shales were more dependent on temperature and less dependent on pressure (Holt et al. 1996; Horsrud et al. 1998).

Figure 8a represents the stress-strain response at $\theta=0^{\circ}$ bedding subjected to the effects of confinement. The material stiffness under CID and CIU tests differed significantly. Under CIU tests, the stiffness curves increased non-linearly up to a certain level and then decreased. A possible reason for this behavior is that the PP develops asymptotically up to a certain level close to the peak stress. The CIU test subjected to drilling normal to bedding would, thus, provide a higher development response of the PP. The developed PP under this test did not account for the effective stress because the volumetric strain was constant. However, for the CID test, the effective stresses play a role in determining the rock strength and stiffness. The initial non-linear trend in Fig. 8a (marked by a dotted elipse) may be due to the presence of induced cracks or natural microfractures. Through the postfailure analysis (Fig. 3) of these samples, it was inferred that the additional induced cracks or microfractures can further contribute to increased pore volume prior to failure. The pore fluid may penetrate through the microfracture network and further reduce the PP, resulting in reduced rock strength. Moreover, the natural properties of shale in terms of crack or microfracture orientation may also produce various nonlinear behaviors. Depending on the loading direction, the fracture network/crack can close or open. This variance leads to a decrease or increase in pore volume in response to the PP. A similar observation was found at $90^{\circ}$ bedding (Fig. 8b). The concave-type CIU test results were mostly defined by the PP increase through the triaxial phase.

The volumetric-axial strain curve (Fig. 9) was used to calculate the Poisson's ratio. The results are presented in
Table 5. For the undrained tests, the value of the Poisson's ratios ranged between 0.34 and 0.75 , while for the drained case, it decreased to 0.2 . This behavior is illustrated and discussed later in this paper.

\subsection{Elastic Moduli of Shale-the CID Case}

The drained test for low permeability rocks is essential to obtain the effective stress parameters. These effective stress parameters are important for borehole stability modeling, especially in shale. Directional stiffness parameters $\left(E_{\mathrm{t}}\right.$ and $\left.E_{\mathrm{p}}\right)$ are essential for the shale anisotropy borehole stability model. The normal or transversal stiffness parameter $\left(E_{\mathrm{t}}\right)$ was determined at sample $\theta=0^{\circ}$ (load normal or transversal to the bedding), and $E_{\mathrm{p}}$ was estimated when $\theta=90^{\circ}$ (loading parallel to the bedding). Søreide et al. (2009) showed analytically that the stiffness for the samples with loading parallel to the bedding $\left(E_{\mathrm{p}}\right)$ is higher than for loading perpendicular to the bedding $\left(E_{\mathrm{t}}\right)$. In our case, the estimated values of $E_{\mathrm{t}}$ and $E_{\mathrm{p}}$ were 0.65 and $1.55 \mathrm{GPa}$, respectively (see Fig. 10a). The estimated mean relative difference of the $E$ between these two samples (in absolute value) was approximately $58 \%$. A significant difference between these two moduli indicated a strong heterogeneous nature.

Figure 10e presents the behavior of the Poisson's ratios for samples at $\theta=0^{\circ}$ and $90^{\circ}$. At $\theta=0^{\circ}$; the observed Poisson's ratios were found to be similar. The two measured radial strains will always be equal because the sample plane acts as a ring and, thus, carries similar material behavior, which produces the same deformations in all directions in that particular plane. In the case of $\theta=90^{\circ}$, the material behavior will be anisotropic, which means that one radial deformation is parallel to the bedding and the other is perpendicular to the bedding. These two measured radial strains will never be equal, and the Poisson's ratios will, therefore, be different. Figure 10e, f supports these conclusions.

The shear modulus is calculated based on the estimated Young's moduli and Poisson's ratios, and the resulting
Fig. 9 Poisson's ratio from axial strain versus volumetric strain through CID tests; a $\theta=0^{\circ}, \mathbf{b} \theta=90^{\circ}$. The dotted circle indicates the strain rate effect due to a temporary stop in the experiment
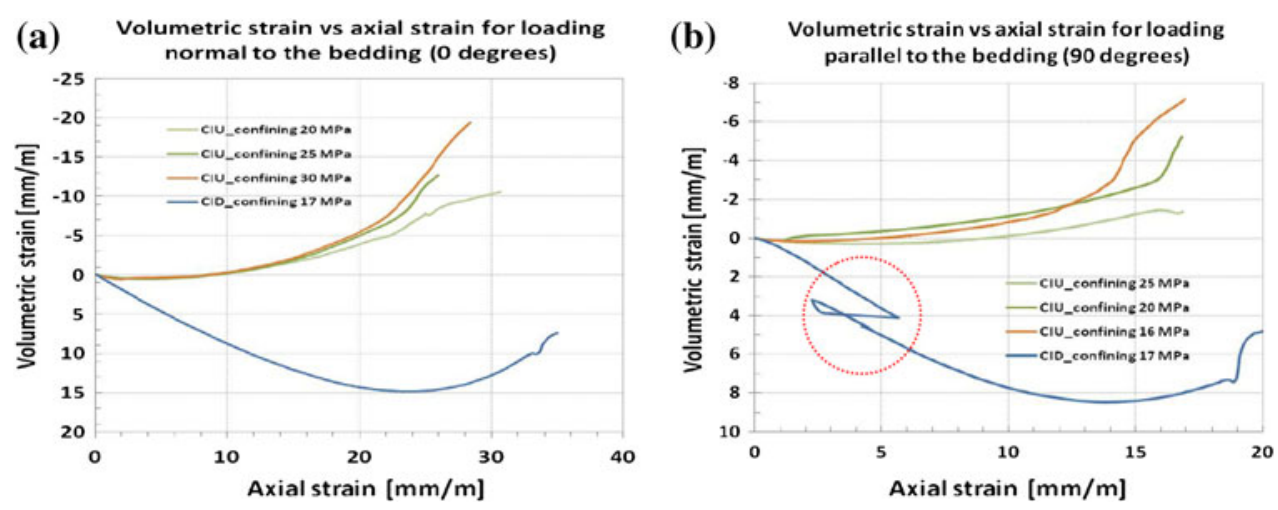
Fig. 10 Shale elastic moduli at drained test conditions; a variation of $E$ with axial strain, b variation of $E$ with deviatoric stress, $\mathbf{c}, \mathbf{d}$ variation of $G$ with axial strain and deviatoric stress, and, finally, $\mathbf{e}, \mathbf{f}$ variation of Poisson's ratios with axial strain and deviatoric stress. The dotted ellipses indicate the abnormal strain rates due to a temporary stop in the experiment
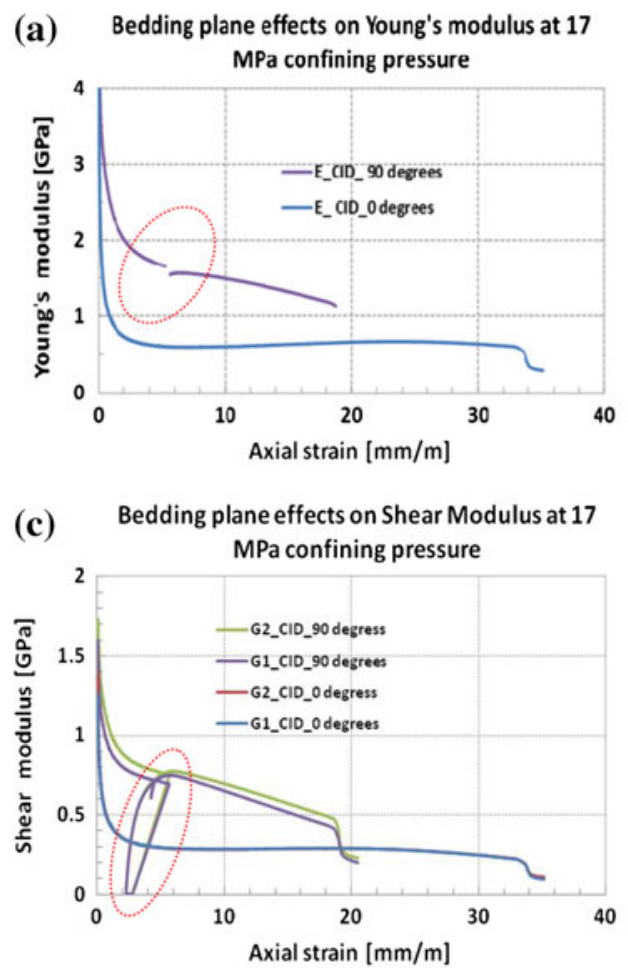

(e) Poisson's ratio at $17 \mathrm{MPa}$ confining pressure

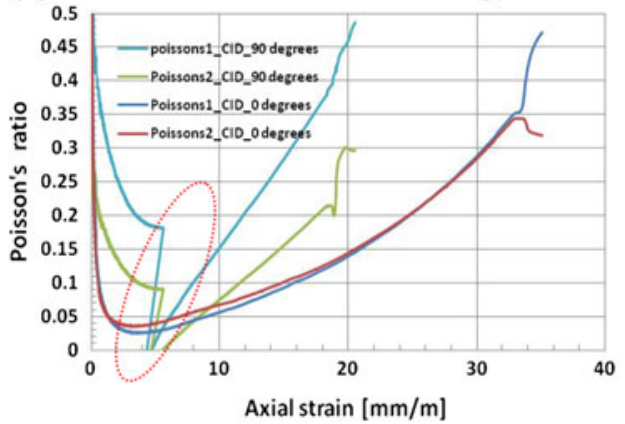

(b) Bedding plane effects on Young's modulus at 17

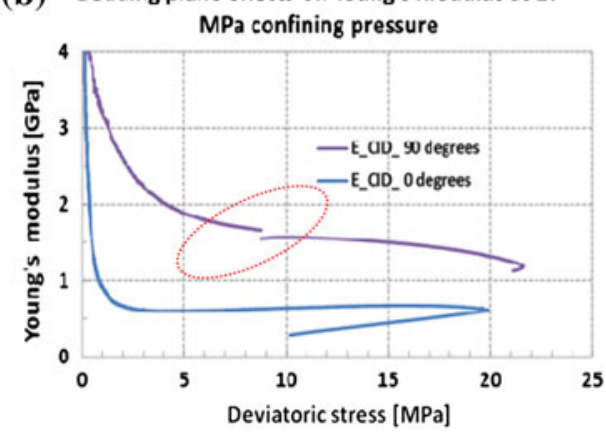

(d) Bedding plane effects on Shear Modulus at 17

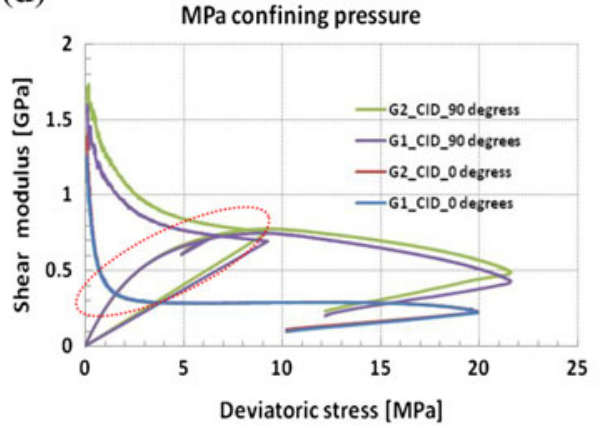

(f) Poisson's ratio at $17 \mathrm{MPa}$ confining pressure

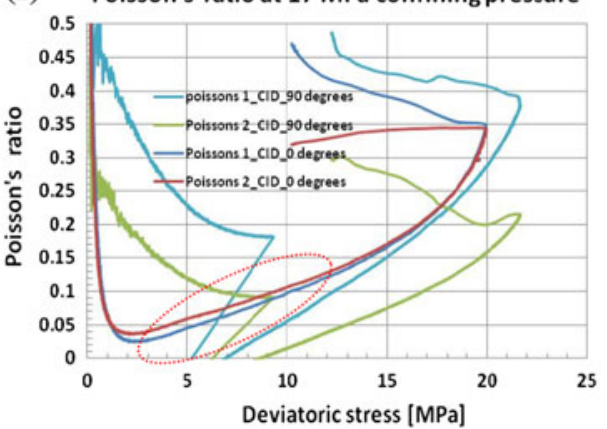

calculations are presented in Fig. 10c, d. The lower limit of the shear modulus for $\theta=0^{\circ}$ was $0.24 \mathrm{GPa}$, but for $\theta=90^{\circ}$, it was $0.62 \mathrm{GPa}$ (on average). In Fig. 10a, b, there is an irregularity, marked by dotted ellipses, caused by stopping the test at a high strain rate. This irregularity may affect the quality of the results. One point that should be carefully addressed is how to select the measured data points. The trend of the Young's modulus at the horizontal bedding is almost linear, but it is non-linear at $\theta=90^{\circ}$.

\subsection{Elastic Moduli of Shale-the CIU Case with Constant Confining Pressure}

At constant confining pressure (i.e., $25 \mathrm{MPa}$ ), the $E$ and the $v$ were calculated and are presented in Fig. 11. The response of the $E$ and $v$ decreased exponentially with increasing axial strain or deviatoric stress. For example, in Fig. 11a, for $10 \%$ axial strain, $E$ for the $90^{\circ}, 60^{\circ}, 45^{\circ}$, and $0^{\circ}$ samples are $2.1,1.7,1.5$, and $1.4 \mathrm{GPa}$, respectively. The samples showed the highest stiffness at $\theta=90^{\circ}$ and the lowest stiffness at $\theta=0^{\circ}$. It is recommended to choose the $E$ data point based on the expected axial strain or deviatoric stress condition.

Two Poisson's ratios were defined, $v_{1}$ and $v_{2}$. The values of $v_{1}$ vary significantly with respect to all bedding plane samples. These values are increasing exponentially but, in some cases, also increasing gradually versus changing deviatoric stress (Fig. 12a, b). For $\theta=0^{\circ}$, the magnitudes of $v_{1}$ and $v_{2}$ followed a non-linear trend and varied from 0.4 to 0.7 . At other sample orientations (except $\theta=0^{\circ}$ ), $v_{1}$ showed extremely high values between 0.6 and 0.8 . However, a significant reduction occurred in the interpreted $v_{2}$, with values varying between 0.25 and 0.4 . At $\theta=0^{\circ}$ and $\theta=90^{\circ}$, the Poisson's ratios $v_{1}=0.52$ and 0.68 , respectively, while $v_{2}$ was calculated to be 0.53 and 0.35 , respectively. 
Fig. 11 Estimation of Young's modulus in CIU tests at different constant confinement pressures

Fig. 12 Estimation of Poisson's ratios in CIU tests at different constant confinement pressures (a) Bedding plane effects on Young's modulus at $25 \mathrm{MPa}$ confining pressure

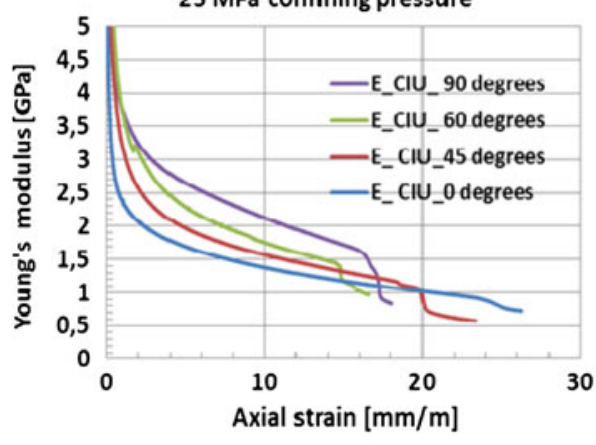

(c) Bedding plane effects on Shear modulus at

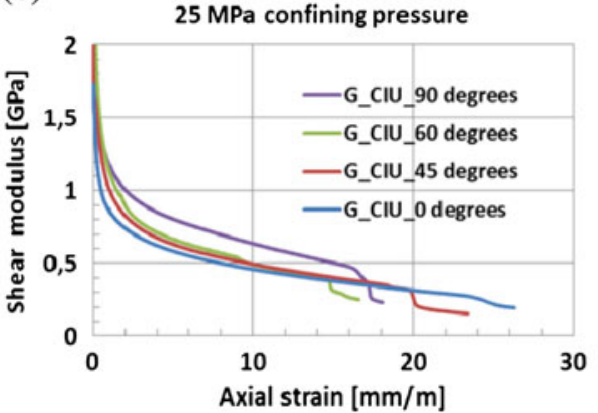

(a) Poisson's ratio -1 at $25 \mathrm{MPa}$ confining
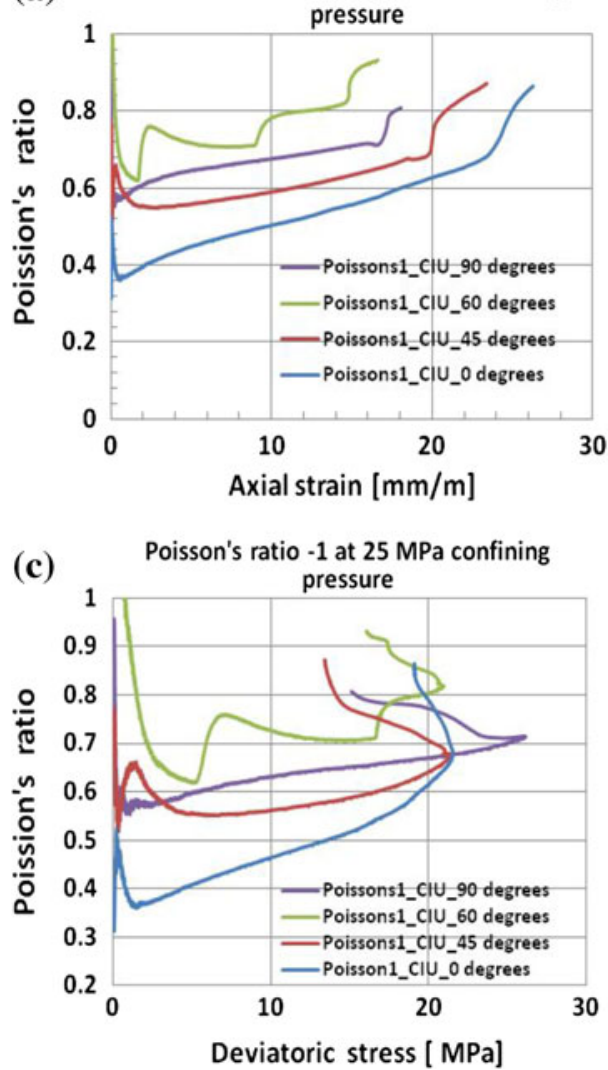

(b) Bedding plane effects on Young's modulus at $25 \mathrm{MPa}$ confining pressure

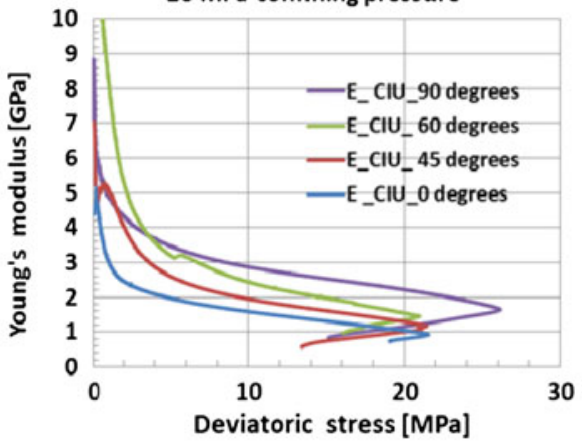

(d) Bedding plane effects on Shear modulus at

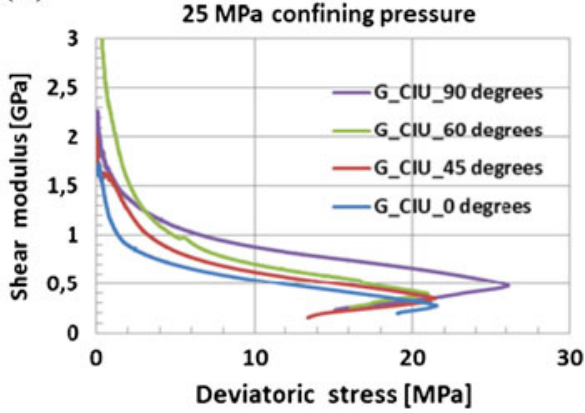

(b) Poisson's ratio -2 at $25 \mathrm{MPa}$ confining

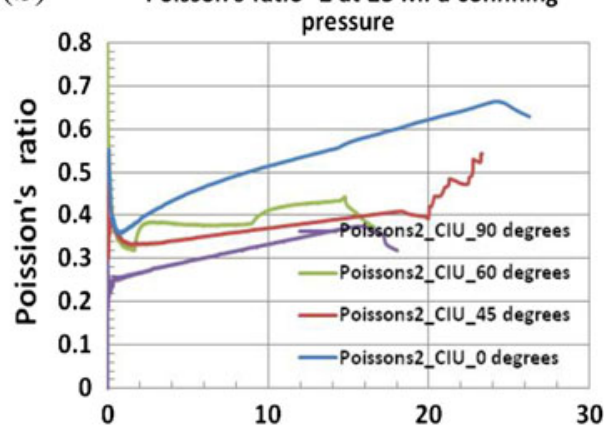

Axial strain $[\mathrm{mm} / \mathrm{m}]$

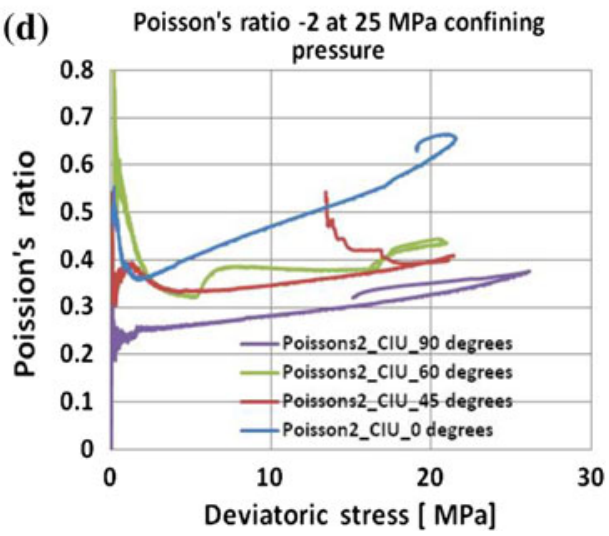


4.5 Effects of Variable Confining Pressure on $E$ (for Both CIU and CID Tests)

The confining pressure influences material stiffness and shear strength. The higher the confining pressure, the stiffer the material and the higher the shear strength. The material stiffness was evaluated by changing the confining pressure, and the interpreted results are presented in Fig. 13. The variation of rock stiffness was clearly observed from this analysis. The material stiffness for the CIU cases gradually decreased with increasing axial strain (Fig. 13a) and with increasing deviatoric stresses (Fig. 13b). Estimates of $E$ for the CIU cases are confusing because it is difficult to find a linear trend, as in the CID cases. The anomaly of the CID curves (dotted circles) is due to a pause in the experiment at a high strain rate and reloading the sample to run the test again. This analysis helped us to choose $E$ according to the projection of confining pressure and material deformation state.

\subsection{Effects of Variable Confining Pressure on v (for Both CIU and CID Tests)}

For homogeneous materials, it is generally accepted that the higher the confining pressure, the higher the Poisson's ratio. Figure $14 \mathrm{a}$ shows that, for samples at $\theta=0^{\circ}$, both $v_{1}$ and $v_{2}$ increased non-linearly with increasing confining pressure. The changing values are minor compared with other bedding orientations.

On the other hand, a large gap between $v_{1}$ and $v_{2}$ was found for the sample drilled at $\theta=90^{\circ}$ (Fig. 14c, d), and similar trends were observed for $\theta=45^{\circ}$ and $60^{\circ}$. At $\theta=90^{\circ}$, values of 0.3 and 0.7 were obtained for $v_{1}$ and $v_{2}$, respectively, and this difference is significant. In the undrained test, the Poisson's ratios observed in the tested shale rocks tended to be larger than 0.5. This observation is supported by Aadnøy and Chenevert (1987), who showed that, for laminated materials, the Poisson's ratio can be higher than 0.5 and is, in fact, dependent on the elasticity modulus ratio (a ratio between the vertical and horizontal moduli).

\section{Cyclic Versus Monotonic Test Effects on Rock Strength}

The CIU test was performed under cyclic loading-reloading, followed by a 4-MPa cyclic amplitude on a sample drilled perpendicular to the bedding $\left(\theta=0^{\circ}\right)$. The idea was to see more of the elastic response during such a small cycle due to non-linearity (Fig. 15c). The test sample for the cyclic test was taken from the same core block used in the previous monotonic samples tested. The cyclic test included 3-4 unloading-reloading cycles. The cycle for each step was $5 \mathrm{MPa}$ during the triaxial phase, with a cycling amplitude of $4 \mathrm{MPa}$. The PP during consolidation was $10 \mathrm{MPa}$, and the confining stress was $25 \mathrm{MPa}$. In the triaxial phase, the strain rate was set to $2 \times 10^{-7} \mathrm{~s}^{-1}$. The test required 4 days to reach yielding.

The postmortem analysis of the sample showed a localization of the deformation in a shear band inclined at an angle of $\theta=45^{\circ}$ to the horizontal bedding plane (Fig. 15a). Under the cyclic triaxial test, the estimated axial stress and the PP at failure was approximately 49 and 16.3 $\mathrm{MPa}$, respectively, which appeared to be fairly consistent with the corresponding established monotonic triaxial test, where the measured values were 46.5 and 17.2 $\mathrm{MPa}$, respectively. Due to cyclic loading, the PP increased $10 \%$ higher than in the monotonic tested samples (Fig. 15g). The slope of the unloading-reloading cycles at different stress levels showed stiffer material when compared with only loading once (Fig. 15e, g). In this particular case, the shale stiffness under cyclic triaxial test conditions was approximately $50 \%$ higher than in the monotonic triaxial test. This increase may be due to an irreversible change in the microstructure of the rock. An irreversible strain (plastic strain) was observed. However, the degradation effects are negligible here because we performed only one cycle and were still well below the peak strength. We cycled at approximately $50 \%$ of the peak stress.

In the cyclic triaxial test condition, an exception was observed in the data for calculating the Poisson's ratio. The two Poisson's ratios were similar under the monotonic triaxial testing, whereas they were completely different in cyclic triaxial test conditions (Fig. 15f). For this particular case, $v_{1}$ and $v_{2}$ were determined to be 0.6 and 0.46 , respectively, for the cyclic test. The possible reasons for such dissimilarity may be the shale heterogeneity or the material deformation state under the cyclic stress state (see Fig. 15c, d). For the static test, the Poisson's ratios were 0.52 and 0.53 , respectively. It was also noticed that the calculated PP under the cyclic triaxial test was lower than for the monotonic triaxial test (Fig. 15g). This study confirmed that the PP plays an adverse role in the determination of the lower stiffness in monotonic tests compared with the cyclic tests. The conclusion is that the PP development is a critical parameter under the CIU tests that can specifically control material stiffness in clay-dominant samples.

There are many factors, i.e., induced cracks and their orientation, partial saturation, material heterogeneity and anisotropy, plasticity, magnitudes of the loading-reloading cycles, strain rate, etc., that could all influence the geomechanical elastic properties of shale. A detailed discussion of the elastic response due to cyclic loading has been 
Fig. 13 a-h Variation of the Young's modulus subjected to variable confinement pressures

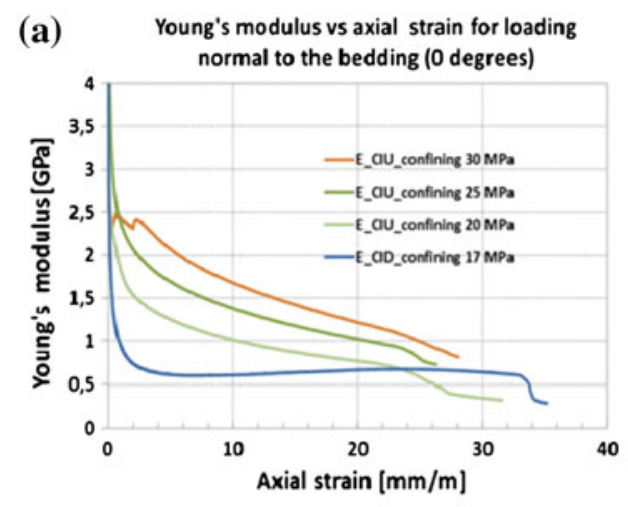

(c) Young's modulus vs axial strain for loading

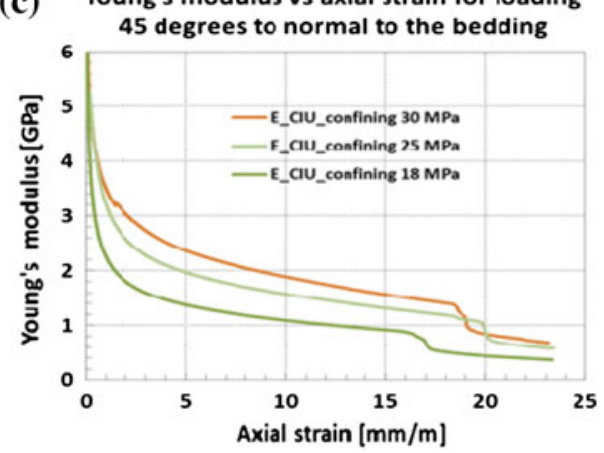

(e) Young's modulus vs axial strain for

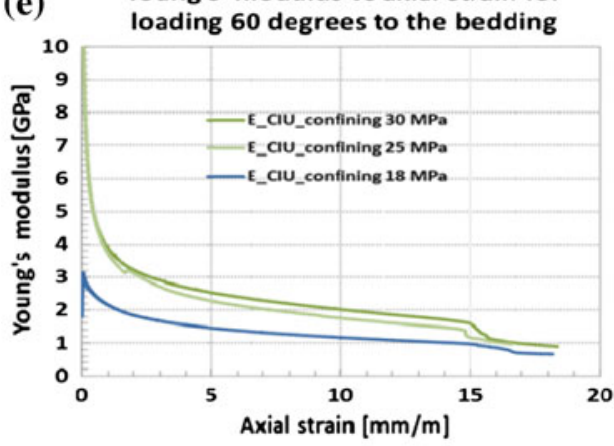

(g) Young's modulus vs axial strain for loading

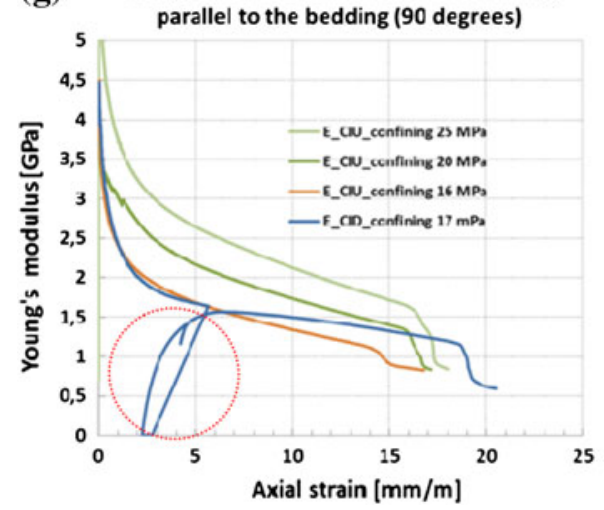

(b) Young's modulus vs deviatoric stress for loading normal to the bedding ( 0 degrees)

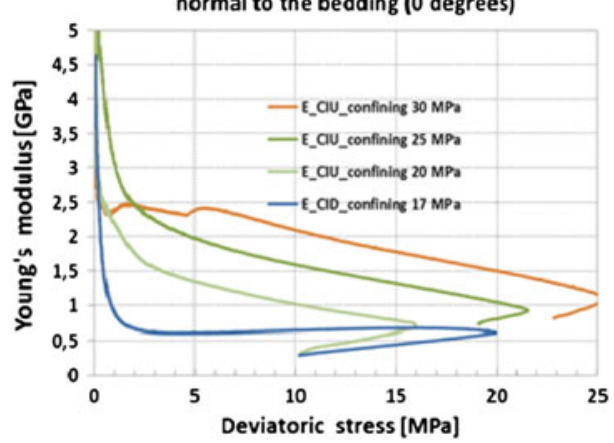

(d)

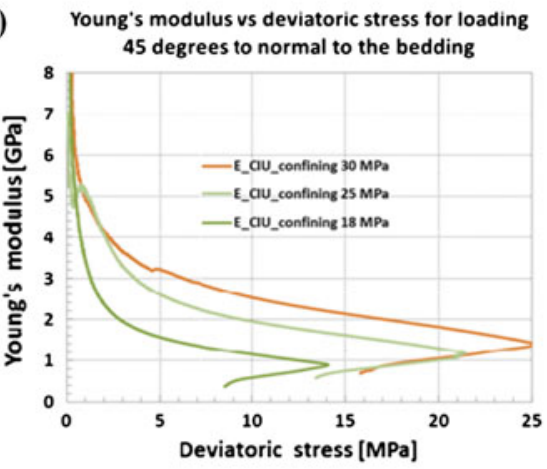

(f) Young's modulus vs deviatoric stress for

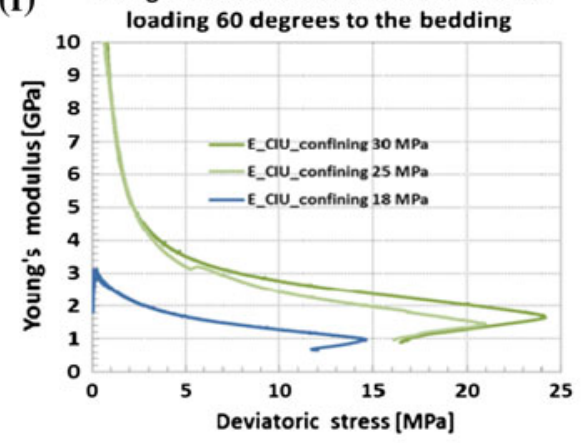

(h) Young's modulus vs deviatoric stress for

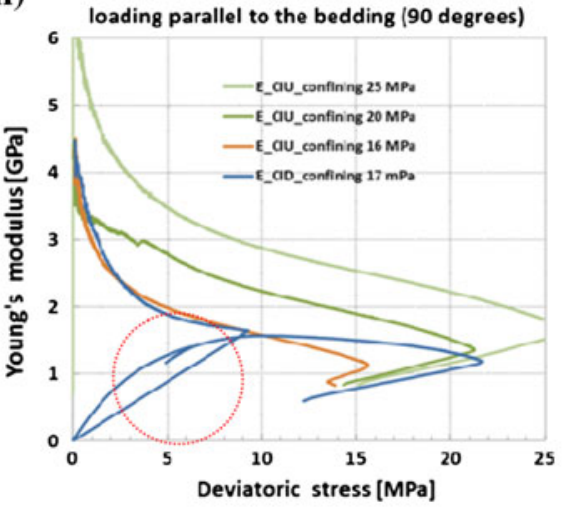

made by Fjær et al. (2008, p. 267), (2011), Holt et al. (2011), and Niandou et al. (1997). From their analysis, the non-elastic behavior during loading is largely dependent on the stress history of the rock.

\section{Rock Deformation Versus Bedding Plane}

A comparative study of the material deformations under shearing on different bedding samples is presented in Fig. 16. 
Fig. 14 a-h Quantifying the effects of confining pressure on the Poisson's ratio
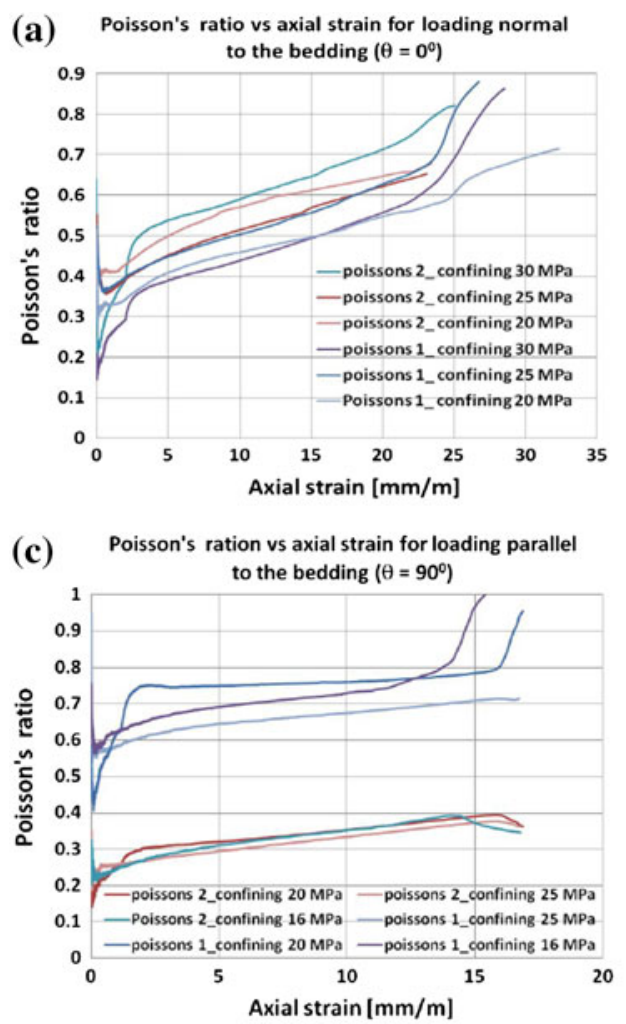

(e) Poisson's ratio vs axial strain for loading $45^{\circ}$ to normal

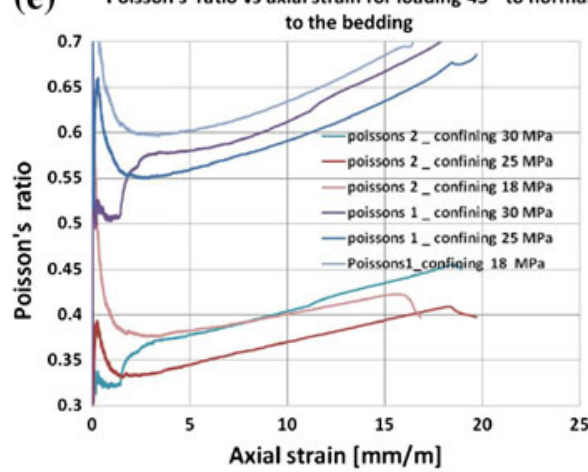

(g) Poisson's ratio vs axial strain for loading $60^{\circ}$ to

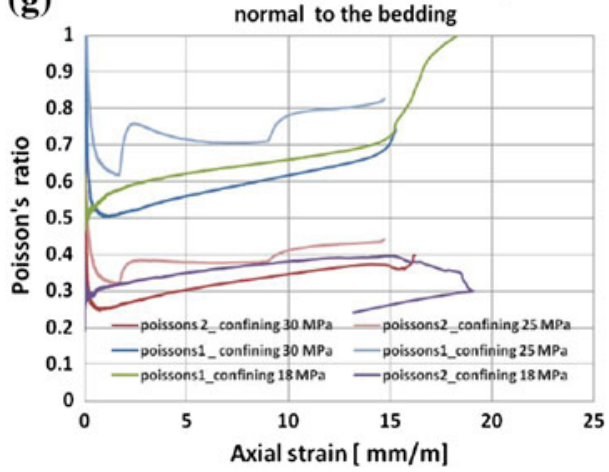

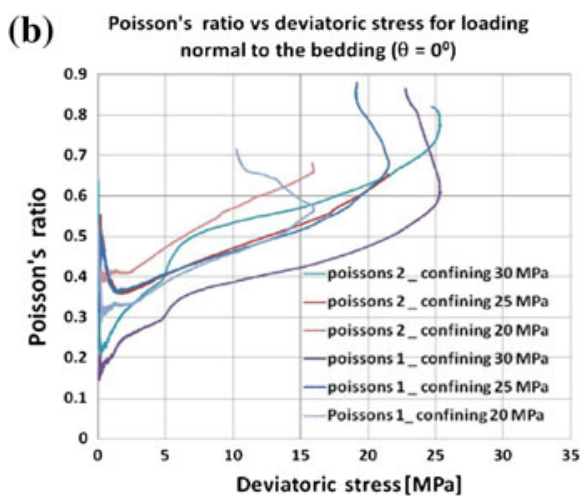

(d) Poisson's ratio vs deviatoric stress for loading

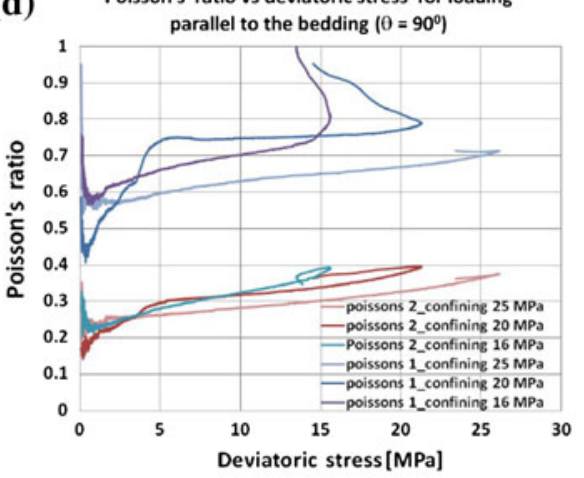

(f) Poisson's ratios vs deviatoric stress for loading $45^{\circ}$ to normal to the bedding

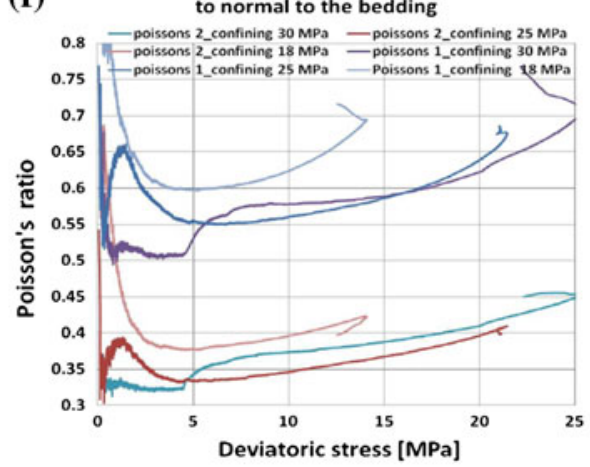

(h) Poisson's ratio vs deviatoric stress for loading

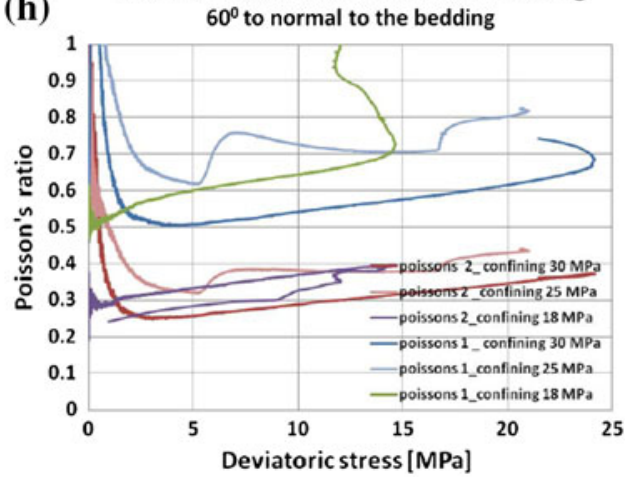

This analysis is interpreted as the peak deviation with respect to axial or radial deformation. Basically, such an analysis helps provide a clear picture of weak bedding in terms of the stiffness. It is observed that the variation of the peak stress varies significantly with the bedding plane orientation. Under the CIU test matrix, the peak deviation is largest for samples drilled parallel to the bedding. The same analysis indicated larger radial deformations but relatively lower peak deviations 
Fig. 15 Comparative studies to evaluate the mechanical properties of shale under cyclic and monotonic test conditions. Postfailure samples a cyclic test and $\mathbf{b}$ monotonic test, $\mathbf{c}$ stiffness curves, $\mathbf{d}$, e $E$ calculation, f variations of Poisson's ratio, and $\mathbf{g}$ PP development and stiffness. All samples were drilled perpendicular to bedding $\left(\theta=0^{\circ}\right)$ (a)

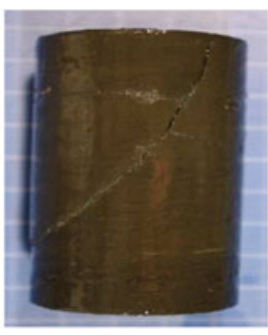

(b)
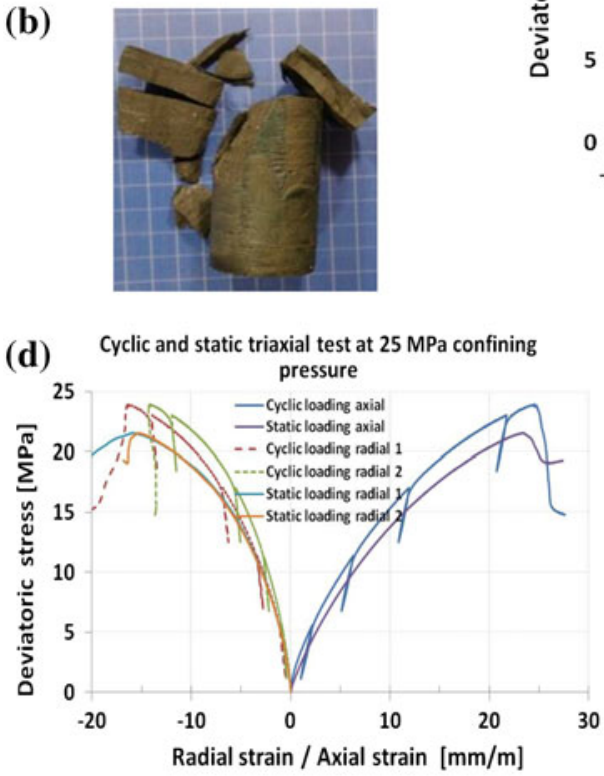

(f) Poisson's ratio at $25 \mathrm{MPa}$ confining pressure,

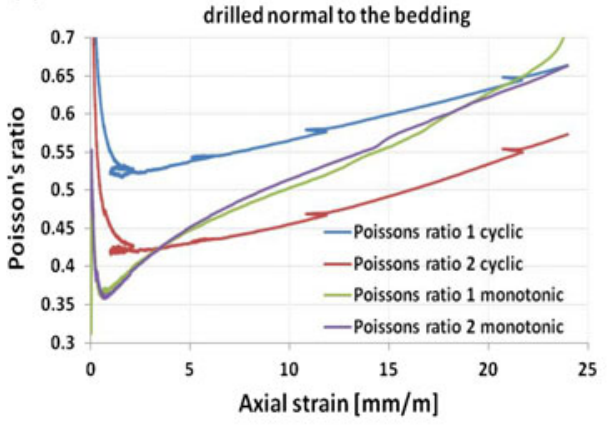

(c) Cyclic and monotonic triaxial test at $25 \mathrm{MPa}$ confining pressure, samples normal to bedding

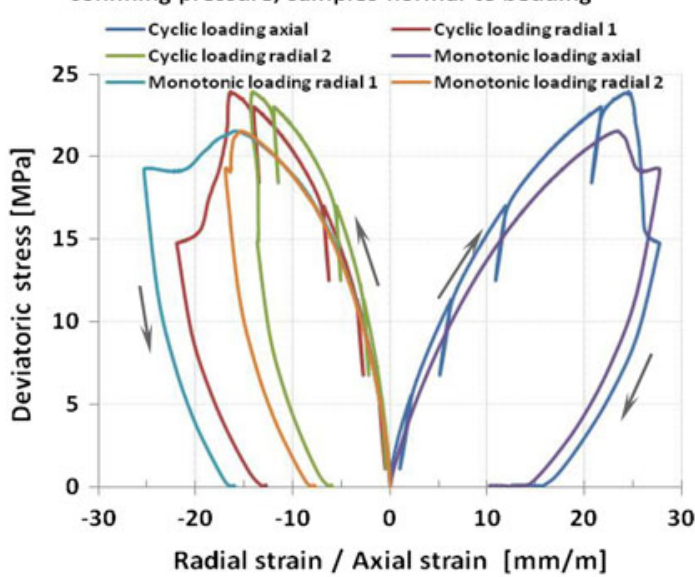

(e) Young's modulus at $25 \mathrm{MPa}$ confining pressure,

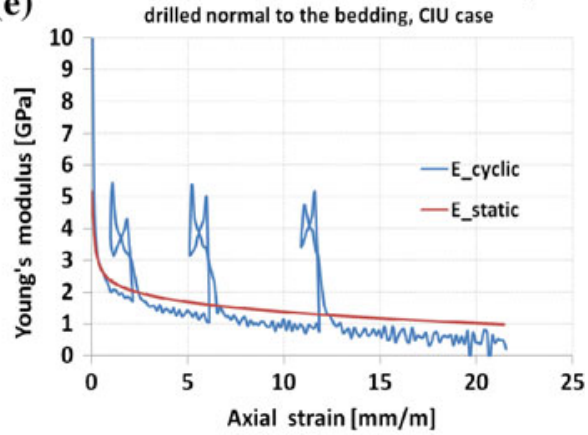

(g) Material stiffness and pore pressure development,

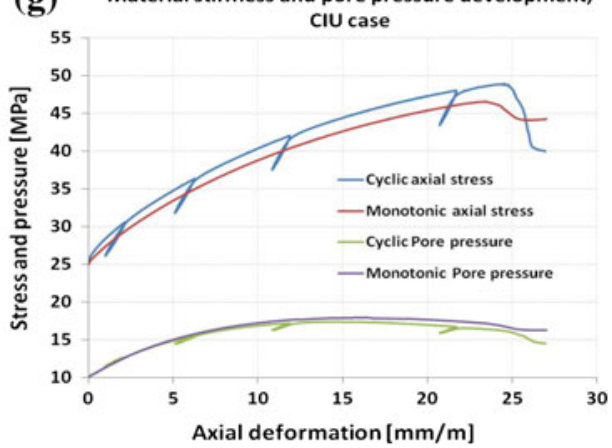

for samples at $0^{\circ}(18 \%)$ and $45^{\circ}(8 \%)$ bedding and, thus, showed lower stiffness. In the case of the CID tests, the maximum axial deformation (35\%) was observed for samples drilled perpendicular to the bedding, whereas it was $20 \%$ for samples drilled parallel to the bedding. Lower stiffness was measured for samples tested under the CID conditions compared with samples tested under the CIU conditions.

\section{Shale Anisotropy}

For an ideal undrained test condition, the effective stress path should be vertical because there is no change in the mean effective stress (zero change in the total volume). The total stress path will then be inclined, and the horizontal change in the mean total stress will be equal to the PP change. However, for the drained case, the PP was constant and the total stress path inclined 3-1 in the $p^{\prime}-q$ diagram (Fig. 17b). This resulted in an inclination of 3-1 for the effective stress path. The shear strength for samples at $\theta=90^{\circ}$ was greater than that for samples at $\theta=0^{\circ}$. For the CIU tests, the total stress path was different from the effective stress path due to the building of the PP. Because the PP was constant for the CID tests, both the total and effective stress paths were identical.

Due to the inherent anisotropic nature of clay platelets (both texturally and mechanically), one would intuitively 


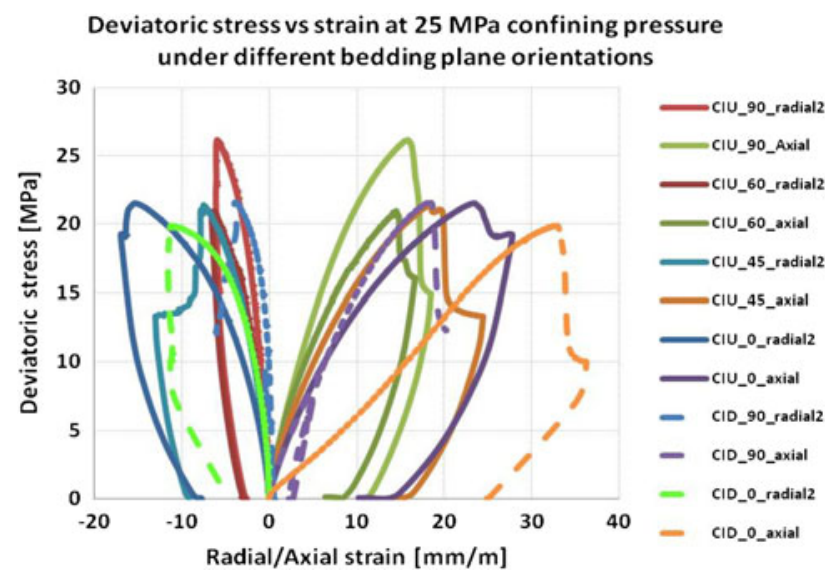

Fig. 16 Stress-strain relationship under different bedding planes

expect shale to be anisotropic. Figure 17a shows the stress paths for two samples at the same effective confining pressure. One of the samples was drilled with the sample axis along the bedding and the other was drilled with the sample axis normal to the bedding. The sample that was drilled parallel to the bedding was both stiffer and stronger than that drilled normal to the bedding (Fig. 17a). With increasing deviatoric stress, the mean effective stress decreased more for the sample at $\theta=0^{\circ}$ due to material contraction. At this position, the pore volumes decreased and led to an increase in the PP with increasing shearing. However, when shearing passed a certain level, i.e., at $15 \mathrm{MPa}$ for this particular case, the material then started to dilate or create cracks or microfractures. These attributes accelerated and caused increasing pore volume and decreasing PP. Samples at $0^{\circ}$ bedding had both contraction and dilation tendencies, whereas for the $90^{\circ}$ bedding, only dilation was observed (Islam 2011). The material drilled parallel to the bedding $\left(\theta=90^{\circ}\right)$ was much stronger, more brittle, and also tilted more to the right side compared to when drilled normal to the bedding $\left(\theta=0^{\circ}\right)$. Therefore, wells drilled at high deviation, i.e., closer to horizontal, and also at larger depths will, thus, be more susceptible to potential stability problems due to the anisotropy.
There are several factors that may affect the degree of anisotropy. One would expect that the larger the clay content, the larger the degree of anisotropy, but this also depends on the mineral type. Both porosity and depth are important. Anisotropy effects were not, however, the main subject of this study. The need for a complete description of the anisotropy of the mechanical properties of shale will depend on the application. Generally, the acoustic properties of shale are significantly influenced by the heterogeneous nature of shale. Many authors have already implicitly analyzed this issue (Horsrud et al. 1994, 1998; Holt et al. 1996; Lockner and Stanchits 2002; Fjær et al. 2008; Sarout et al. 2007).

\section{Pore Pressure Response}

The non-elastic behavior of tested shale through the unloading-reloading cycle is presented in Sect. 5. The stress path behavior is observed to be different between the cyclic and static tests, and the elastic moduli vary significantly. However, the non-elastic behavior of the tested shale under the undrained situation is governed by the PP development. The PP response during the testing of shales may indicate whether the sample is fully saturated. To quantify the PP response $\left(\Delta P_{\mathrm{f}}\right)$, the Skempton parameters $A$ and $B$ can be defined, as suggested by Skempton (1954):

$\Delta P_{\mathrm{f}}=B\left[\Delta \sigma_{3}+A\left(\Delta \sigma_{1}-\Delta \sigma_{3}\right)\right]$

For triaxial loading conditions, the mean effective stress can be expressed as

$\Delta \sigma_{m}^{\prime}=\frac{1}{3} \frac{\Delta P_{\mathrm{f}}}{A B}-\Delta P_{\mathrm{f}}$

with the change in the mean effective stress during triaxial loading yielding $\sigma_{m}^{\prime}=\Delta P^{\prime}$.

For the poroelastic case where $k_{\mathrm{f}} \ll k_{\mathrm{s}}, A B$ can be expressed by elastic constants (Fjær et al. 2008), as suggested by
Fig. 17 Stress path and material anisotropy effects under a CIU response and b CID response
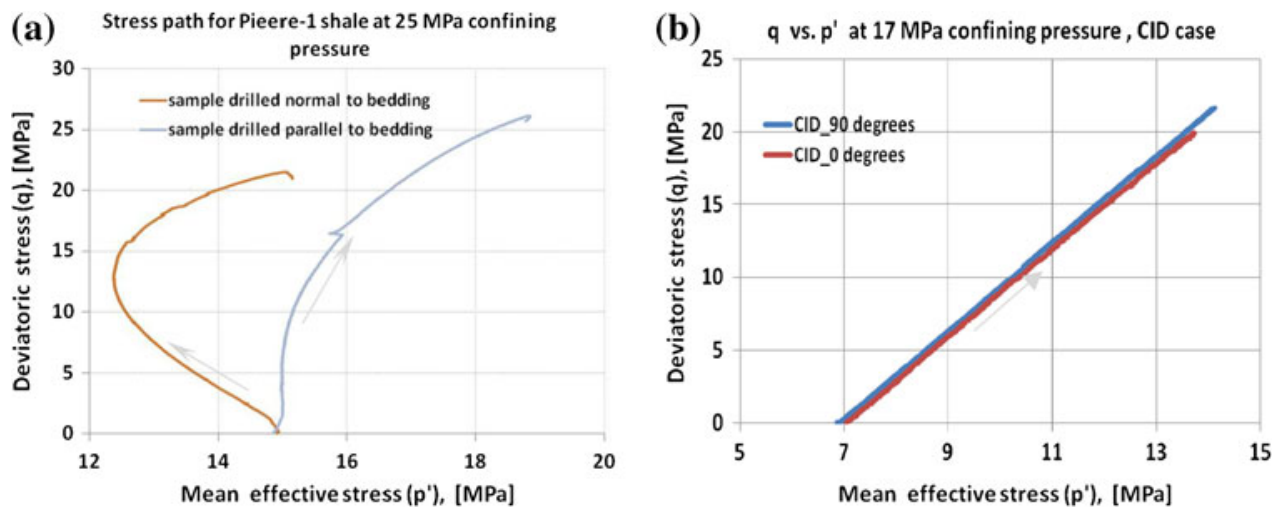
$A B=\frac{1}{3}\left[\frac{1}{1+\frac{\varphi k_{\mathrm{fr}}\left(1-\frac{k_{\mathrm{f}}}{k_{\mathrm{s}}}\right)}{\alpha k_{\mathrm{f}}}}\right]$

where $\varphi$ is the fractional porosity, $\alpha$ is the Biot coefficient $\left(=1-k_{\mathrm{fr}} / k_{\mathrm{s}}\right), k_{\mathrm{fr}}$ is the bulk modulus of the framework, and $k_{\mathrm{f}}$ is the fluid modulus.

The analytical expression (Eq. 3) can be used to explain the non-elastic response of the tested shale because this equation can now be related to the stress paths of the $p^{\prime}-$ $q$ plots (Figs. 17a, 18). With $\varphi k_{\mathrm{fr}} \ll \alpha k_{\mathrm{f}}, A B=1 / 3$ from Eq. 2 and $\Delta P^{\prime}=0$; thus, the curve in the undrained triaxial test is vertical. This result is commonly referred to as the 'weak frame limit', which is the common assumption for any soil. According to Skempton (1954), for a soil in the elastic case, it can be shown that $A=1 / 3$ and $B=1$. In this study, no vertical stress path was found, the weak frame assumption did not hold, and $A B \neq 1 / 3$.

If $A B<1 / 3$, from Eq. $2, \Delta P^{\prime}=(-\mathrm{m}) \Delta P_{\mathrm{f}}$, where $\mathrm{m}$ is a multiplier factor and is less than 1 . As a result, the stress path curves will tilt to the right, as shown in Fig. 18a (only loading parallel to bedding). In most cases, the stress path tilts slightly (i.e., at bedding angles of $45^{\circ}$ and $60^{\circ}$ ) or more inclined (i.e., $0^{\circ}$ ) to the left (see Fig. 18). This behavior can be justified if $\Delta P^{\prime}<0$.

Examining Eq. 3, the only solution to this equation is if $k_{\mathrm{f}}>k_{\mathrm{s}}$, which is not realistic. This type of behavior, thus, indicates that the rock is no longer elastic. This is, for instance, the case for a normally consolidated material such as shale. Several authors also presented the PP response in sandstone-based rock strength in different ways (Skempton 1954; Horsrud et al. 1994, 1998; Lockner and Stanchits
2002; Fjær et al. 2008). However, in the end, the same conclusion was noted.

\section{Interpretation of the Mohr-Coulomb Failure Parameters from the Triaxial Tests}

The Mohr-Coulomb failure criterion satisfies linear elastic condition. It is simpler than other models but, at the same time, the most widely used criterion in the oil industry. The material failure parameter, i.e., cohesion and uniaxial compressive strength (UCS), can be interpreted from the triaxial tests with existing mathematical expressions. For example, the $\tau-p^{\prime}$ space interprets cohesion directly, while the $\beta=\frac{\pi}{4}+\frac{\varphi}{2}$ space provides the UCS. Sometimes, the $q-p^{\prime}$ space is used, but it provides neither the cohesion nor the UCS directly. To use the $q-p^{\prime}$ space to evaluate the material failure parameters for the Mohr-Coulomb model, the parameter relation is rearranged:

$q=2 S_{0}+2 \tan \phi \sigma_{1}^{\prime}$

Here, $q$ is the deviatoric stress, $S_{0}$ is the inherent shear strength or cohesion, $\phi$ is the internal friction angle, and $\sigma^{\prime}$ is the mean effective stress. The parameter UCS $\left(C_{0}\right)$ and the failure angle $(\beta)$ are related through

$C_{0}=2 S_{0} \tan \beta$

These equations determine the Mohr-Coulomb model input parameters $\left(\phi, \beta, C_{0}\right)$. The peak stress values in Fig. 18 falls essentially on a straight line. In soil mechanical terms, this is a projection of the Hvorslev surface onto the $p^{\prime}-q$ plane (for a specific given volume). A
Fig. 18 CIU test of Pierre-1 shale, showing the MohrCoulomb failure lines from laboratory tests and estimating Mohr-Coulomb failure parameters; a loading parallel to bedding $\left(\theta=90^{\circ}\right)$, b loading perpendicular to bedding $\left(\theta=0^{\circ}\right)$, c loading $45^{\circ}$ to the normal to bedding $\left(\theta=45^{\circ}\right)$, and $\mathbf{d}$ loading $60^{\circ}$ to the normal to bedding $\left(\theta=60^{\circ}\right)$. The anomalies marked by the dotted circles were caused by the test performances
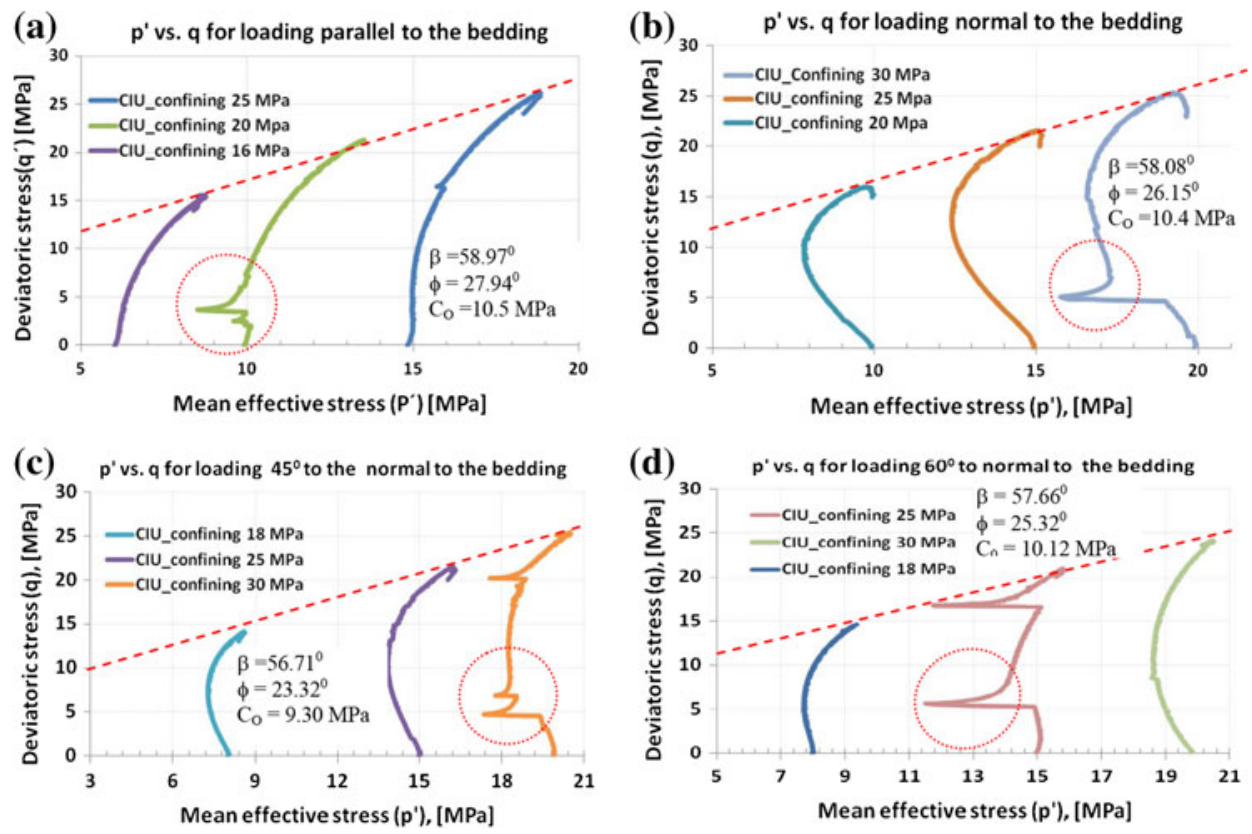
uniform clay sample obeying the critical state theory would follow the Hvorslev surface up to the critical state line. Overconsolidated and cemented rocks will eventually behave in a non-uniform manner. This was clearly the case for the samples shown in Fig. 18. When approaching the peak stress value, localization took place, and shear bands developed, which eventually formed a macroscopic shear plane through the sample. The behavior after the peak was, thus, in this case, more dependent on the characteristics typical of a rock (e.g., cementation) rather than a soil. In addition, the dotted circles on the stress paths indicate rapid PP development, which are due to strain rate effects or to existing cracking. The straight lines in Fig. 18 could be translated into a Mohr-Coulomb failure criterion, providing an extrapolated UCS, failure angle, and friction angle. A set of Mohr-Coulomb failure model data is shown in Fig. 18. The friction angle appears to be high for the CIU tests for the relatively soft shale. Similar analysis was performed for different bedding plane orientations and at different confining pressures. The observed results are presented in Fig. 18. Depending on the bedding plane, Fig. 18 implies that the UCS varied between 9.3 and $10.5 \mathrm{MPa}$, and the failure angle varied between $23.4^{\circ}$ and $27.9^{\circ}$. In the case of North Sea shale, studied by Horsrud et al. (1994), the UCS varied between 6 and $77.5 \mathrm{MPa}$, and the failure angle $(\beta)$ ranged between $48^{\circ}$ and $60^{\circ}$. The Young's modulus $(E)$ correlated with a UCS of $6.55 E\left(R^{2}=0.99\right)$. Aadnøy et al. (2009) reported that $E$ for green river shale in Canada varied between 60 and $160 \mathrm{GPa}$.

It is difficult to explain the exact reasons behind the high frictional angles obtained in the CIU tests. In the CIU tests, we worked with Pierre-1 shale, which has high heterogeneity. We believe that we obtained a higher frictional angle due to the frictional behavior. However, partial saturation could also lead to a high frictional angle (Sønstebø and Horsrud 1996; Schmitt et al. 1994). We cannot guarantee that the test samples for this outcrop achieved $100 \%$ saturation. We carefully attempted to obtain good saturation with brine as a contacting pore fluid, as reported in Sect. 2.1. The sample should also improve its saturation during the mechanical loading. Some of the apparent plastic behavior may be related to the low permeability and PP development during loading.

The Mohr-Coulomb failure parameters and the necessary correlations developed through this study are presented in Fig. 19. Both the CIU and CID test results are presented. The $90^{\circ}$ bedding samples seem to have the strongest correlation, whereas the $45^{\circ}$ bedding samples have the weakest correlation.

\section{Potential Applications}

The rock strength behavior of the shale tested under drained and undrained conditions is considered to be a challenging and costly task. The most obvious application of this study is to supply data sets for numerical borehole stability modeling in shale. The mechanical properties of shale are demanding parameters not only for drilling engineering purposes but also in the geomechanical field. For example, the Poisson's ratio is often used within geophysics and sanding prediction. Experimental results and theoretical considerations have shown that the Poisson's
Fig. 19 Mohr-Coulomb failure lines connected for different bedding planes. The different colors are indications of the respective failure trend lines of the different bedding plane samples

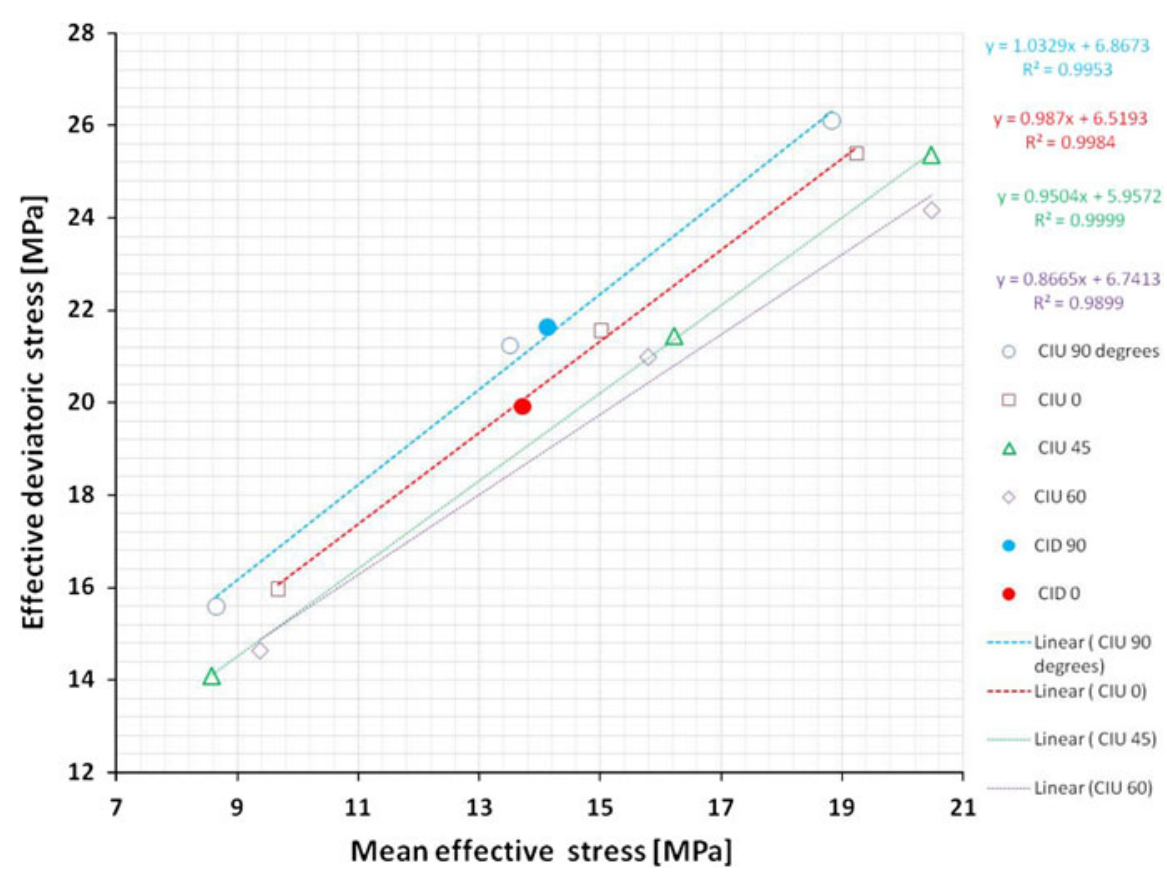


ratio is not a single-valued, well-defined parameter for a given rock. The same observations were observed for measurements of the Young's modulus. Young's moduli for drained/undrained conditions varied largely with the stress level and with the amplitude and duration of the applied stress changes. Because the Poisson's ratio represents the relationship between the $\mathrm{P}$ and $\mathrm{S}$ waves in the identification of lithology from the seismic data and the AVO analysis, finding a suitable value of this parameter is vital, particularly at interbedded formations.

In recent years, the shale-oil and shale-gas potential represents new unconventional assets where shale-related information could be valuable for other researchers working in this field. The same aspect is true for the underground storage of $\mathrm{CO}_{2}$. Our analysis will be useful for such issues. As a result, rock failure analysis was included in this work. The contribution relating to caprock failure data and shale characterization could be used for updating existing borehole stability analysis models. Obviously, improved shale property information under drained and undrained test conditions would improve model efficiency and accuracy. Very few studies have considered such extensive test matrices in shale. Moreover, this study provides some correlations between the material friction angle and the UCS. Because the UCS can be calculated from the sonic logs, such correlation can be implemented more readily. This correlation may be useful in the field of petroleum engineering with more testing under field conditions.

A dedicated testing program for Pierre-1 shale has provided a valuable database for shale properties, especially for weaker shale, which may cause borehole-stability problems. The correlations developed in this study can be used as an engineering tool to provide more reliable and more continuous estimates of the mechanical properties of shale, keeping in mind that the validity of the correlations should be verified when used in other geological and geophysical areas. Other sources of uncertainty also exist (e.g., core damage effects, temperature effects, etc.) and should be a focus in further work.

\section{Conclusions}

This study supplied data sets to implement an anisotropic material model that was used to simulate shale rocks. An isotropic model cannot simulate the real material behavior and, thus, should not be considered adequate. The anisotropic behavior is primarily due to the bedding planes that are formed, and because a borehole can be made at any angle to those planes, one should be able to simulate the real anisotropic behavior at any angle to the bedding plane. Thus, care should be taken when simulating such rock masses. The elastic moduli of such masses should never be considered as constant in all directions; instead, as the tests showed, we must expect them to vary considerably. This study also showed the dependency of the material on the confining stress. Obviously, the correct confining stress must be derived and used to simulate the real behavior as closely as possible.

Transverse isotropic shale has generally been studied experimentally using triaxial tests subjected to globally axisymmetric loading states, although the true stress states will not be axisymmetric due to the bedding plane inclination, inhomogeneities in the specimens, and end-effects. This study showed that the planes of weakness in bedded rocks could lead to severe borehole collapse problems.

The key findings of this study were elaborately presented in every section. However, the most crucial observations are listed here:

- Cyclic triaxial tests provided approximately $6 \%$ higher rock strength, $50 \%$ higher stiffness, and $10 \%$ higher PP development than the only monotonic triaxial loading test. PP controls the rock stiffness under the CIU tests.

- Poisson's ratio effects in the samples drilled parallel to bedding are more vital than at any other sample orientation. A large variation in Poisson's ratios was found for drained and undrained samples drilled at the same bedding angle in transverse isotropic material. For the undrained fluid flow condition, the Poisson's ratios were observed in the tested shale rocks to be larger than 0.5 and varied between 0.3 and 0.75 . However, for the drained case, the maximum limit of Poisson's ratios was 0.2. Therefore, in the case of shale, merely assuming a constant Poisson's ratio is a risky approach.

- The elastic moduli are non-linear functions of the confining pressure but are also dependent on the effective stress. $E_{\mathrm{p}}$ (loading parallel to bedding) was higher than $E_{\mathrm{t}}$ (loading perpendicular to bedding). The estimated values of $E_{\mathrm{t}}$ and $E_{\mathrm{p}}$ were 0.65 and $1.55 \mathrm{GPa}$, respectively. The estimated mean relative difference of the $E$ for these two samples (in absolute value) was approximately $58 \%$. A significant difference between these two moduli indicates a strong heterogeneous nature.

- The elastic moduli for drained and undrained test conditions varied largely. The drained Young's modulus was approximately $48 \%$ of the undrained value. The drained Poisson's ratios were, on average, $40 \%$ or lower than the undrained value. These mechanical properties were significantly impacted by the bedding plane orientation and the confinement pressure.

- The bedding plane, anisotropy, and material heterogeneity are three prime factors to achieve accurate estimation of the material failure and development of the PP. 
- The dilation behavior is significant under the drained test conditions. At low confinement pressure, the failure is brittle, with a sudden loss of strength and a transition from compressive to dilatants volumetric strain during failure and postfailure.

- The time dependency of parameters is significant due to the low permeability of shale.

Acknowledgments The authors thank the Department of Petroleum Engineering and Applied Geophysics, Norwegian University of Science and Technology, for their support and providing the permission to write this paper. We would like to express our appreciation to Ole Kristian Søreide and Per Horsrud of STATOIL, and Jørn Stenebråten, Erling Fjær, and Olav-Magner Nes of SINTEF Petroleum Research for their contribution to the discussions of critical issues in this work. We especially thank Konstantinos Kalomoiris. His help greatly improved our work. A thorough peer review and constructive comments by the reviewers are also appreciated and acknowledged. It further helped us to improve the quality of the paper. We thank STATOIL for providing funds for the experimental investigation of borehole stability. In addition, we appreciate and acknowledge the extensive laboratory work that was performed and partially funded by SINTEF Petroleum Research.

Open Access This article is distributed under the terms of the Creative Commons Attribution License which permits any use, distribution, and reproduction in any medium, provided the original author(s) and the source are credited.

\section{References}

Aadnøy BS, Chenevert ME (1987) Stability of highly inclined boreholes. In: Proceedings of the IADC/SPE drilling conference, New Orleans, Louisiana, 15-18 March 1987, SPE 16052

Aadnøy BS, Hareland G, Kustamsi A (2009) Borehole failure related to bedding plane. In: Proceedings of the ARMA conference, Asheville, North Carolina, 28 June-1 July 2009

Bradley WB (1979) Failure of inclined boreholes. J Energy Resour Technol 101:232-239

Claesson J, Bohloli B (2002) Brazilian test: stress field and tensile strength of anisotropic rocks using an analytical solution. Int $\mathrm{J}$ Rock Mech Min Sci 39:991-1004

Closmann PJ, Bradley WB (1979) The effect of temperature on tensile and compressive strengths and Young's modulus of oil shale. In: Proceedings of the SPE-AIME 52nd annual fall technical conference and exhibition, Denver, Colorado, 9-12 October 1977, SPE 6734

Crook AJL, Yu J-G, Willson SM (2002) Development of an orthotropic 3D elastoplastic material model for shale. In: Presented at the SPE/ISRM rock mechanics conference, San Antonio, Texas, 20-23 October 2002

Fjær E, Holt RM, Horsrud P, Raaen AM, Risnes R (2008) Petroleum related rock mechanics, 2nd edn. Elsevier, Amsterdam, p 267

Fjær E, Holt RM, Nes O-M (2011) The transition from elastic to nonelastic behavior. In: Presented at the 45th US rock mechanics/ geomechanics symposium, San Francisco, CA, 26-29 June 2011

Head KH (1984) Soil laboratory testing, vol I-III. ELE Int., London

Hoang SK, Abousleiman YN (2010) Openhole stability and solids production simulation of emerging gas shales using anisotropic thick wall cylinders. In: Proceedings of the IADC/SPE Asia
Pacific drilling technology conference and exhibition, Ho Chi Minh City, Vietnam, 1-3 November 2010, IADC/SPE 135865

Horsrud P (1998) Estimating mechanical properties of shale from empirical correlations. J SPE 16(2):68-73

Horsrud P, Holt RM, Sonstebo EF, Svano G, Bostrom B (1994) Time dependent borehole stability: laboratory studies and numerical simulation of different mechanisms in shale. In: Presented at the Eurock SPE/ISRM rock mechanics in petroleum engineering conference, Delft, The Netherlands, 29-31 August 1994

Horsrud P, Sønstebø EF, Bøe R (1998) Mechanical and petrophysical properties of North Sea shales. Int J Rock Mech Min Sci 35(8): 1009-1020

Holt RM, Sønsteb $\varnothing$ EF, Horsrud P (1996) Acoustic velocities of North Sea shales. In: Proceedings of the 58th EAGE conference and technical exhibition, Amsterdam, The Netherlands, 3-7 June 1996

Holt RM, Fjær E, Nes O-M, Alassi HT (2011) A shaly look at brittleness. In: Presented at the 45th US rock mechanics/ geomechanics symposium, San Francisco, California, 26-29 June 2011

Hofmann CE, Johnson RK (2006) Estimation of formation pressures from log-derived shale properties. J Petrol Technol 17:717-722

Islam MdA (2011) Modeling and prediction of borehole collapse pressure during underbalanced drilling in shale. Ph.D. thesis at NTNU, Norway. ISBN 978-82-471-2599-1

Islam MdA, Skalle P, Faruk ABM, Pierre B (2009) Analytical and numerical study of consolidation effect on time delayed borehole stability during underbalanced drilling in shale. In: Proceedings of the KIPCE 09/SPE drilling conference, Kuwait City, Kuwait, 14-16 December 2009, SPE 127554

Jaeger JC, Cook NGW (1979) Fundamentals of rock mechanics, 3rd edn. Chapman and Hall, New York

Johnston DH (1987) Physical properties of shale at temperature and pressure. Geophysics 52:1391-1401

Katsube TJ, Mudford BS, Best ME (1991) Petrophysical characteristics of shales from the Scotian shelf. Geophysics 56:1681-1689

Lockner DA, Stanchits SA (2002) Undrained poroelastic response of sandstones to deviatoric stress change. J Geophys Res 107(B12): 2353. doi:10.1029/2001JB001460

Loret B, Rizzi E, Zerfa Z (2001) Relations between drained and undrained moduli in anisotropic poroelasticity. J Mech Phys Solids 40:2593-2619

Maury V, Santarelli FJ (1988) Borehole stability: a new challenge for an old problem. In: Cundall PA, Sterling RL, Starfield AM (eds) Key questions in rock mechanics. Balkema, Rotterdam, pp 453-460. ISBN 9061918359

Nakken SJ, Christensen TL, Marsden R, Holt RM (1989) Mechanical behaviour of clays at high stress levels for well bore stability applications. In: Maury V, Fourmaintraux D (eds) Rock at great depth. Balkema, Rotterdam, pp 141-148

Nes O-M, Sønstebø EF, Holt RM (1998) Dynamic and static measurements on mm-size shale samples. In: Proceedings of Eurock 98, Trondheim, Norway, Trondheim, 8-10 July 1998, pp 23-32, vol 2, SPE/ISRM 47200

Niandou H, Shao JF, Henry JP, Fourmaintraux D (1997) Laboratory investigation of the mechanical behavior of tournemire shale. Int J Rock Mech Min Sci 34(1):3-16

Papamichos E, Brignoli M, Santarelli FJ (1997) An experimental and theoretical study of a partially saturated collapsible rock. Mech Cohes Frict Mater 2:251-278

Rozhko AY (2011) Capillary phenomena in partially-saturated rocks: theory of effective stress. In: Presented at the 45th US rock mechanics/geomechanics symposium, San Francisco, California, 26-29 June 2011

Sarout J, Molez L, Guéguen Y, Hoteit N (2007) Shale dynamic properties and anisotropy under triaxial loading: experimental and theoretical investigations. Phys Chem Earth 32:896-906 
Schmitt L, Forsans T, Santarelli FJ (1994) Shale testing and capillary phenomena. Int J Rock Mech Min Sci Geomech Abstr 31: 411-427

Skempton AW (1954) The pore-pressure coefficients A and B. Geotechnique 4:143-147

Sønstebø EF, Horsrud P (1996) Effects of brines on mechanical properties of shales under different test conditions. In: Proceedings of Eurock 96, Turin, Italy, 2-5 September 1996. Balkema, Rotterdam, pp 91-98

Søreide OK, Bostrøm B, Horsrud P (2009) Borehole stability simulations of an HPHT field using anisotropic shale modeling.
In: Proceedings of the ARMA conference, Asheville, North Carolina, June 28-July 12008

Spaar JR, Ledgerwood LW, Hughes C, Goodman H, Graff RL, Moo TJ (1995) Formation compressive strength estimates for predicting drillability and PDC bit selection. In: Presented at the SPE/ IADC drilling conference, Amsterdam, The Netherlands, 28 February-2 March 1995, SPE/IADC 29397

Steiger RP, Leung PK (1992) Quantitative determination of the mechanical properties of shales. SPE Drill Eng 7:181-185

Wood DM (1990) Soil behaviour and critical state soil mechanics. Cambridge University Press, Cambridge 